\title{
Long-term modelling of the thermal-hydraulic-mechanical response of a generic salt repository for heat-generating nuclear waste
}

Laura Blanco Martín*, Jonny Rutqvist, Jens T. Birkholzer

Earth Sciences Division, Lawrence Berkeley National Laboratory, 1 Cyclotron Rd, MS

74R316C, Berkeley, CA 94720, USA

"Corresponding author. Tel.: +15104865456; fax: +15104865686

E-mail addresses: lblancomartin@lbl.gov, irutqvist@lbl.gov, itbirkholzer@lbl.gov 


\section{Abstract}

A modelling effort has been undertaken to investigate the long-term response of a generic salt repository for heat-generating nuclear waste, including processes that could affect the geological (natural salt host rock) and geotechnical (backfill) barriers. For this purpose, the TOUGH-FLAC sequential simulator for coupled thermal-hydraulic-mechanical processes modelling has recently been provided with a capability for large strains and creep. The responses of the saliferous host rock and the crushed salt backfill are modelled using dedicated constitutive relationships. Similarly, the coupling between the geomechanics and the flow subproblems is performed on the basis of theoretical and experimental studies. The repository investigated in this work considers in-drift emplacement of the waste packages and subsequent backfill of the drifts with run-of-mine salt. Using the updated TOUGH-FLAC, the compaction of the backfill and the evolution of its properties as porosity decreases can be modelled. Additionally, different processes that may influence the initial tightness of the host rock can be investigated. On the basis of state-of-the-art phenomenological models, our simulation results show that, in order to evaluate the barriers integrity, it is necessary to consider full coupling between thermal, hydraulic and mechanical processes. A base case scenario that accounts for these coupled processes is presented and compared to a case in which the mechanical processes are disregarded. Also, we investigate the sensitivity of the coupled numerical predictions to two factors: the initial saturation within the host rock and the capillary forces. Although the outcome of these simulations is preliminary and will be improved as the understanding of relevant salt processes moves forward, the numerical tools required to perform the target predictions have been significantly improved.

\section{Keywords}

Nuclear waste disposal, natural salt, crushed salt, large strains, numerical modeling, coupled processes 


\section{Introduction}

Rock salt is a potential medium for the underground disposal of nuclear waste because of several assets, in particular its near-zero primary permeability (i.e., undisturbed salt is water and gas tight), its very low porosity, its high ductility, its healing capacity and its relatively high thermal conductivity as compared to other shallow-crustal rock types (Bechthold et al., 1999; Carter et al., 2011a; Hardin and Voegele, 2013; Hou, 2003; Hunsche and Hampel, 1999). Moreover, rock salt is usually found underground in large volumes in stable geological areas and is easy to mine. Additionally, the run-of-mine salt may be used to backfill mined open emplacement areas (Carter et al., 2011a).

Because of these advantages, rock salt has been studied since the 1960s, and, since 1999, it is being used for disposal and isolation of defense-related transuranic nuclear waste (equivalent to long-lived, intermediate-level waste) at the WIPP site (Waste Isolation Pilot Plant)

(DOE/WIPP, 2002). Furthermore, in Germany a complete safety assessment analysis has been recently performed for the Gorleben site, describing all aspects which are of importance for a heat-generating nuclear waste repository in rock salt (Mönig et al., 2013).

In the current research, attention is being focused on heat-generating nuclear waste (such as used nuclear fuel or high-level waste). The work presented in this paper has been developed within the framework of the US Department of Energy Used Fuel Disposition Campaign (Nutt et al., 2011). One of the missions of this campaign is to conduct scientific research to enable underground disposal of used nuclear fuel and high-level waste generated by existing and future nuclear fuel cycles. Initially, the campaign focuses on generic research that will support future site-specific work. Accordingly, we have considered a generic salt repository (GSR) with in-drift emplacement of the waste packages and subsequent backfill of the drifts with crushed (run-of-mine) salt. In such a scenario, the crushed salt backfill gets progressively compacted as the natural salt creeps. Once the reconsolidation process is over, it is expected that the backfill 
will provide a geotechnical barrier (Bechthold et al., 2004; Wieczorek et al., 2012), thereby reinforcing the natural barrier function of the host rock. In this context, the ultimate goal of the present research is to evaluate the long-term integrity of the geological (host rock) barrier, as well as the development and long-term integrity of the geotechnical (backfill) barrier. Indeed, in the unfavorable event of a radionuclide release from the waste packages, these barriers are essential to prevent the escape and the transport of undesired fluids into the biosphere. Key parameters of barrier integrity are permeability and porosity (Hansen, 2008; Schulze et al., 2001).

As for the natural salt, it is well known that its initial tightness could be affected by processes that take place at different stages during the lifetime of a repository (Hou, 2003; Hunsche and Hampel, 1999; Peach and Spiers, 1996; Schulze et al., 2001; Stormont and Daemen, 1992; Wolters et al., 2010). First, the development of an excavation damaged zone (EDZ) around the mined openings represents a potential risk because preferential flow pathways could be created. Thermo-mechanical damage occurs if the dilatancy boundary is exceeded (Minkley and Popp, 2010; Wolters et al., 2012). Second, a pore pressure-driven percolation process (fluid infiltration) can take place if the pore pressure locally exceeds the minimum compressive principal stress. Several factors can result in fluid permeation: thermal pressurization within the rock (due to thermal expansion of pore fluids that cannot escape in a very low-permeability medium - this is particularly true when the pore space is mostly occupied by low compressibility fluids, such as water or brine), convergence-induced pore pressure increase, and gas generation from the waste packages, among others. Should thermo-mechanical damage or fluid infiltration occur, the initial, near-zero permeability of the host rock would be superseded by an increased, secondary permeability (Wieczorek et al., 2012; Wolters et al., 2012). These perturbations, however, are generally not persistent in a plastic medium such as rock salt. Once the stress regime becomes favorable, healing takes place. Healing processes consist in the 
development of cohesion between former crack planes (in extension of pore space closure). They decrease damage by helping bond fracture surfaces and close micro-fractures (Hansen, 2008; Popp et al., 2012; Wolters et al., 2012), i.e., salt damage is reversible (Hansen, 2008). Additionally, local widening of grain boundaries caused by percolation of pore fluids ceases as the pore pressure decreases below the minimum compressive principal stress (Wolters et al., 2012). Damage, healing and percolation processes within natural salt have been thoroughly studied at the laboratory scale and have been included in advanced, validated constitutive relationships (Hampel et al., 2013; Wolters et al., 2012). They have also been observed in various field studies (Bechthold et al., 2004; GRS, 2001; Hou, 2003; Popp and Minkley, 2010).

The reconsolidation process of the crushed salt used for backfill has also been studied in the past years, and several time-dependent compaction models have been proposed (Callahan et al., 1998; Olivella and Gens, 2002; Sjaardema and Krieg, 1987). As compaction takes place, the mechanical and flow properties of the crushed salt evolve towards those of the natural salt. In particular, permeability decreases several orders of magnitude, the thermal conductivity increases and so do the elastic moduli (Bechthold et al., 2004; Bechthold et al., 1999; Callahan et al., 1998; Hurtado et al., 1997; Wieczorek et al., 2012). Experimental studies have shown that the compaction rate increases with the moisture content (Popp and Salzer, 2012). On the other hand, the reconsolidation process at the high temperatures associated with exothermic nuclear waste would benefit from further investigation (Carter et al., 2011a). Moreover, the compaction behavior at porosities lower than $5-10 \%$ is not currently well understood, and data in this range are scarce (Kröhn et al., 2012).

The safety assessment of a repository for nuclear waste requires the demonstration of the integrity of the geological and geotechnical barriers. For such demonstration, thermal, hydraulic, 
mechanical (and chemical) processes need to be considered. These processes interact and influence each other in a complex manner. In addition, they do not necessarily have the same spatial and temporal scales; therefore, numerical modelling using proper tools is needed (Tsang et al., 2009). Several modelling studies on the disposal of heat-generating nuclear waste in saliferous formations have been reported in the literature (Argüello and Rath, 2013, 2012; Bechthold et al., 2004; Bechthold et al., 1999; Clayton et al., 2012; Hampel et al., 2013; Javeri and Baltes, 2008; Kock et al., 2013; Lerch et al., 2012; Lowe and Knowles, 1989; Munson et al., 1990; Pudewills et al., 1995; Stone et al., 2010). Nevertheless, the majority of these studies do not consider simultaneously important thermal, hydraulic and mechanical processes. In this research, we seek to improve the current understanding of the long-term integrity of the natural salt and the crushed salt by considering coupled thermal-hydraulic-mechanical (THM) processes. The TOUGH-FLAC sequential simulator for flow and geomechanics (Rutqvist and Tsang, 2003) has been adapted to predict the long-term response of a generic salt repository for heat-generating nuclear waste. In particular, the updated version of the simulator is able to deal with the large strains induced by the compaction of the backfill and the creep of the natural salt. State-of-the-art constitutive relationships and coupling functions between flow and geomechanical processes have been implemented.

This paper is organized as follows. First, the updated version of TOUGH-FLAC for coupled processes in saliferous media is described. Then, the constitutive relationships selected to model the long-term response of the natural salt and the crushed salt are presented, together with relevant flow and mechanical properties and their interrelated evolution. Such evolution is based on previous laboratory and field investigations. Next, the long-term response of the generic salt repository considered in this study is predicted using the new version of TOUGHFLAC. After a description of the model and the simulation set-up, THM results of a base case scenario are presented and discussed. The predictions include the stages of excavation, waste 
emplacement, backfilling and post-closure (100 000 years).Then, we compare results from THM and TH simulations to evaluate the relevance of the coupling to mechanical processes (in particular, fluid infiltration, damage and healing processes within the host rock, as well as backfill compaction). This comparison supports the need to develop a simulator able to deal with coupled THM processes, including large strains and creep. Finally, we investigate the sensitivity of the THM predictions to two factors: the initial saturation within the host rock and the strength of the capillary forces.

\section{Materials and Methods}

\subsection{The TOUGH-FLAC simulator for large strains and creep}

The TOUGH-FLAC simulator has been developed at Lawrence Berkeley National Laboratory (Rutqvist and Tsang, 2003) and is based on an explicit sequential method to couple flow and geomechanics. The multiphase fluid and heat flows are computed by TOUGH2 (Pruess et al., 2011) and the geomechanical response of the system is calculated using FLAC ${ }^{3 D}$ (Itasca, 2009). TOUGH-FLAC has been successfully used in different application fields, including nuclear waste disposal, geological carbon sequestration and geothermal reservoir engineering (Rutqvist, 2011; Rutqvist et al., 2002).

The coupling scheme between TOUGH2 and FLAC ${ }^{3 \mathrm{D}}$ is based on the fixed stress-split sequential method (Kim et al., 2011). In this method, the flow problem is solved first (with an explicit evaluation of the volumetric total stress) and the pore pressure and the temperature are prescribed during the geomechanical calculation, which therefore requires drained mechanical properties. The fundamentals of fully coupled and sequential approaches can be found in the literature (Jeannin et al., 2007; Jha and Juanes, 2007; Settari and Mourits, 1998; Settari and Walters, 2001), as well as discussions of the main advantages of sequential methods (Dean et al., 2006; Felippa and Park, 1980; Thomas et al., 2003; Vijalapura et al., 2005). 
The applicability of TOUGH-FLAC to study coupled THM processes in saliferous media has required some modifications to the simulator. In particular, significant volume changes may result not only from the backfill reconsolidation, but also from the possible damage and healing processes within the natural salt. Also, the viscoplastic rheology of both materials may entail severe mesh distortions. While $\mathrm{FLAC}^{3 \mathrm{D}}$ is able to deal with large strains, TOUGH2 adaptation to large strains has required some modifications in the mass and heat balance equations. Currently, the modelling sequence is as follows. TOUGH2 moves the simulation forward and $\mathrm{FLAC}^{3 \mathrm{D}}$ is executed once within a TOUGH2 time step, just before the Newton-Raphson iteration process to solve the residual nonlinear equations. A schematic view of the coupled THM modelling sequence is displayed in Fig. 1 . The pressure, $P^{n}$, temperature, $T^{n}$, liquid saturation, $S_{I}{ }^{n}$, and porosity, $\phi^{n}$, of each grid block computed at the end of the previous time step (from $t^{n-1}$ to $t^{n}$ ) are transferred to FLAC ${ }^{3 \mathrm{D}}$. Note that the pressure transferred depends on the definition of pore pressure and effective stress in multiphase systems (Coussy, 2004; Kim et al., 2013). From flow to geomechanics, the pore pressure change, $\Delta P=P^{n}-P^{n-1}$, and the temperature change, $\Delta T=T^{n}-T^{n-1}$, corresponding to two successive TOUGH2 time steps are accounted for as a correction to the total stress tensor, $\sigma_{i j}$ (direct coupling). These changes are computed internally in FLAC ${ }^{3 \mathrm{D}}$ once the new values $P^{n}$ and $T^{n}$ are transferred from TOUGH2. The corrected total stress tensor, $\sigma_{i j}^{c}$, has the form

$$
\sigma_{i j}^{c}=\sigma_{i j}-\alpha \Delta P \delta_{i j}-3 \alpha_{T} K \Delta T \delta_{i j}
$$

where $\alpha[-]$ is the Biot coefficient of the material, $\alpha_{T}\left[\mathrm{~K}^{-1}\right]$ is its linear thermal expansion coefficient, $K[\mathrm{MPa}]$ is its bulk modulus and $\delta_{i j}[-]$ is the Kronecker delta. Compressive stresses are defined negative here. From Eq. (1), it can be inferred that the coupling from flow to geomechanics only affects the volumetric component of the stress tensor. Porosity and liquid saturation are used to update the body forces in the quasi-static governing equations of the 
geomechanical analysis (see, e.g., Kim et al. (2012)). Note that these equations account for the thermal strains that result from the temperature change $\Delta T$.

Once all the updates are made, $\mathrm{FLAC}^{3 \mathrm{D}}$ runs in creep and large-strain modes from time $t^{n-1}$ to time $t^{n}$. A new equilibrium mechanical state is obtained at time $t^{n}$ (stresses $\sigma^{n}$ and strains $\varepsilon^{n}$ in Fig. 1). Recall that during the mechanical calculation, the flow data $\left(P^{n}, T^{n}, S_{l}{ }^{n}\right.$ and $\left.\phi^{n}\right)$ remain constant.

From geomechanics to flow, geometrical changes are first accounted for. The geometrical data updated in TOUGH2 are: volume of the elements, distances of the centroids of two connected elements to their common interface, common interface area, and cosine of the angle between the gravitational acceleration vector and the line passing through the centroids of two connected elements. Moreover, we have extended the mass and heat balance equations to account for possible volume changes. Additionally, porosity variations during the current time step (i.e., from $t^{n}$ to $t^{n+1}$ in Fig. 1) are computed in TOUGH2 using a formulation of coupled geomechanics and multiphase fluid and heat flows, adapted from Kim et al. (2012). This analytical formulation is an extension of the classic thermodynamical approach implemented in TOUGH2 and includes a porosity correction term that accounts for geomechanical effects (via the volumetric component of the total stress tensor).

Additionally, the new mechanical state obtained at $t^{n}$ is used through several coupling functions to compute mechanically induced changes in permeability and capillary pressure ( $\Delta k$ and $\Delta P_{c}$ in Fig. 1). The coupling functions depend on each material (and the phenomena it goes through) and should be based on specific laboratory and theoretical results; they will be described in sections 2.2 and 2.3 for the natural salt and the crushed salt respectively. The mechanically modified flow properties $\left(k^{\prime n}, \phi^{\prime n}\right.$ and $P_{c}^{\prime n}$ in Fig. 1) are used to solve the residual equations of the flow problem. Within a time step, the Newton-Raphson iteration process is continued until the residuals are reduced below a preset convergence tolerance. At the end of the current time 
step (time $t^{n+1}$ in Fig. 1), a new set of primary thermodynamic variables $\left(P^{n+1}, T^{n+1}\right.$ and $S_{l}{ }^{n+1}$ in Fig. 1) and new flow properties $\left(k^{n+1}, \phi^{n+1}\right.$ and $P_{c}{ }^{n+1}$ in the figure) are obtained.

Finally, it should be noted that, while in this research it has been decided to update directly the geometrical data in the flow simulator (updated Lagrangian method), other approaches are possible (Bathe et al., 1975; Coussy, 1995). The main alternative consists in keeping the initial geometry as a reference and in mapping pertinent properties onto that initial configuration (total Lagrangian method). While both total and updated Lagrangian methods are mathematically equivalent, the total Lagrangian method is thought to reduce computational cost. Research is currently being undertaken on this topic (Rutqvist et al., 2013).

\subsection{Thermal, hydraulic and mechanical characteristics of the natural salt}

Rock salt is known to creep under the effect of temperature and deviatoric stresses, and also to experience thermo-mechanically induced damage and fluid permeation if certain stress thresholds are exceeded (Hou, 2003; Hunsche and Hampel, 1999; Minkley and Popp, 2010; Popp and Minkley, 2010; Schulze et al., 2001; Wolters et al., 2010). In order to predict the longterm response of a nuclear waste repository, a reliable extrapolation of the behaviour observed in a shorter time scale is necessary. Such extrapolation should be performed on the basis of constitutive relationships with a physical foundation.

In this research, we use the Lux/Wolters constitutive model for rock salt (Hou, 2003; Hou and Lux, 2000, 1999, 1998; Hou et al., 1998; Lux, 1984; Wolters et al., 2012). This model is based on continuum damage mechanics and has been established using a series of laboratory investigations designed to study, from a macroscopic viewpoint, the mechanisms involved in the short- and long-term responses of rock salt. The Lux/Wolters model has been validated against field and laboratory scale data (Hou, 2003; Wolters et al., 2010) and has been implemented as a user-defined model in FLAC ${ }^{3 D}$. 
In the $L u x /$ Wolters model, the total strain rate tensor, $\varepsilon_{i j}$, is composed of the superposition of four strain rate tensors issued from different mechanisms: elastic, viscoplastic, damage-induced and healing processes. The total strain rate tensor reads

$\varepsilon_{i j}=\varepsilon_{i j}^{e}+\varepsilon_{i j}^{v p}+\varepsilon_{i j}^{d}+\varepsilon_{i j}^{h}$

where superscripts $e, v p, d$ and $h$ stand for elastic, viscoplastic, damage and healing, respectively. All the components of the strain rate tensor defined in Eq. (2) take a damageinduced reduction of the load-bearing cross-sectional area into account, in accordance with a previous study (Kachanov, 1986). Equations of the Lux/Wolters model can be found in Wolters et al. (2012). As compared to classical models developed to describe the mechanical behaviour of rock salt (Chan et al., 1997; Cristescu, 1993; Munson, 1997, among others), one originality of the Lux/Wolters model is its capability to account for healing processes. Also, the Biot coefficient is damage-dependent. Other state-of-the-art constitutive models for rock salt are described in Hampel et al. (2012).

The damage-free viscoplastic strain rate tensor, $\varepsilon_{i j}^{v p}$, is purely deviatoric (i.e., there are no volumetric changes related to viscoplasticity). The viscoplastic response is modelled using the Lubby2 model (Lux, 1984). As compared to the nonlinear Burgers model-that accounts for transient and stationary creep (Kelvin and Maxwell elements, respectively)—in the Lubby2 model the parameters are dependent on both stress and temperature.

The damage strain rate tensor, $\varepsilon_{i j}^{d}$, comes into play if there is an excess of either tensile or shear stresses beyond a failure (or dilatancy) boundary. The tensile strength of rock salt is small (typically $<5 \mathrm{MPa}$ ). The shear strength is a function of the minimum principal stress and the Lode angle. The damage strain rate tensor has a non-zero volumetric component (i.e., damage 
causes a non-elastic volume change, also referred to as dilatancy). The analytical formulation of the damage-induced strain rate tensor conforms to the plasticity theory, with a non-associated flow rule.

The last component of the strain rate tensor, $\varepsilon_{i j}^{h}$, accounts for damage healing. Healing reduces dilatancy and damage, but cannot occur while damage (shear or tensile yielding) is taking place. Moreover, some damage is necessary before healing can actually start. According to laboratory observations, the recovery of damage in the Lux/Wolters model is faster at the beginning of the healing process (due to a rapid volume contraction), while in a second stage slower mechanisms such as re-crystallisation or diffusion dominate, cf. Hou, (2003). In the current version of the model, humidity effects are not accounted for.

The damage dependence of the Biot coefficient is also included in the model. In the undisturbed state, the Biot coefficient of rock salt is often considered to be very close to zero (Hou, 2002), but increases as damage takes place. On the other hand, healing can restore the initial Biot coefficient. From the interpretation of laboratory scale results, the evolution of the Biot coefficient is described by (Hou, 2002; Kansy, 2007)

$$
\alpha_{\text {salt }}=\max \left(\frac{D}{D_{\alpha}}, 1-\exp \left(\frac{\sigma_{v} m D}{D-D_{\alpha}}\right)\right)
$$

where $D[-]$ is a damage parameter (Hou, 2002; Wolters et al., 2012), $D_{\alpha}=0.1$ [-] is a constant, $\sigma_{V} \geq 0[\mathrm{MPa}]$ is von Mises equivalent stress and $m<0\left[\mathrm{MPa}^{-1}\right]$ is a parameter that enhances Maxwell viscosity (Maxwell viscosity is a parameter in rheological viscoplastic models and decreases if either temperature or equivalent stress increases. Following Wolters et al. (2012), parameter $m$ determines the influence of the equivalent stress on Maxwell viscosity). In total, the Lux/Wolters constitutive model needs 34 parameters (Lerche, 2012). However, the number of parameters used in a simulation may be reduced depending on the phenomena under investigation. 
From the perspective of heat flow, experimental results on salt rock mass suggest that the rock grain specific heat and the thermal conductivity are dependent on temperature. The evolution of the specific heat is described by

$C=855+0.177 T$

where $T\left[{ }^{\circ} \mathrm{C}\right]$ and $C\left[\mathrm{~J} \cdot \mathrm{kg}^{-1} \cdot \mathrm{K}^{-1}\right]$ (Bechthold et al., 1999). On the other hand, the thermal conductivity of the natural salt has been found to decrease with temperature. From experimental evidence (Bechthold et al., 1999), the evolution may be described using

$\lambda_{\text {salt }}=5.734-1.838 \cdot 10^{-2} T+2.86 \cdot 10^{-5} T^{2}-1.51 \cdot 10^{-8} T^{3}$

In Eq. (5), $T\left[{ }^{\circ} \mathrm{C}\right]$ and $\lambda_{\text {salt }}\left[\mathrm{W} \cdot \mathrm{m}^{-1} \mathrm{~K}^{-1}\right]$.

Finally, laboratory and field investigations on rock salt have confirmed that there exist two independent mechanisms that could cause a loss of the natural barrier integrity (Popp and Minkley, 2010; Wolters et al., 2012). These mechanisms are likely to modify key parameters of fluid migration, such as permeability and porosity (Cosenza and Ghoreychi, 1999; Wolters et al., 2010). First, thermo-mechanically induced damage occurs if the dilatancy boundary is exceeded (this likely takes place in the EDZ). Several laboratory investigations show that the secondary permeability developed is a very nonlinear function of dilatancy (Peach and Spiers 1996; Popp and Kern, 1998; Stormont and Daemen, 1992; Wolters et al., 2010). From these investigations, a porosity-permeability relationship (or secondary permeability function) has been formulated (Wolters et al., 2010) as follows

$$
k_{\text {salt }}^{\text {secondary }}=10^{\log \left(k_{\min }^{\text {secondary }}\right)+\left\langle\log \left(\varepsilon_{v o l}\right)-\log \left(\varepsilon_{\text {vol }, 0}\right)+d \exp \left(f \sigma_{\perp 2}^{\prime}\right) \frac{1}{\ln (10)}\left(\operatorname{Ei}\left(e \varepsilon_{v o l}\right)-\operatorname{Ei}\left(e \varepsilon_{v o l, 0}\right)\right)\right\rangle} k^{*}
$$

with $\langle x\rangle=x$ if $x>0$ and $\langle x\rangle=0$ otherwise. Parameter $k_{\min }^{\text {secondary }}\left[\mathrm{m}^{2}\right]$ is the minimum secondary permeability at the onset of thermo-mechanically induced damage, $\varepsilon_{v o l} \geq 0[-]$ is dilatancy $\left(\varepsilon_{v o l, 0}[-]\right.$ is the initial dilatancy, i.e., the dilatancy limit at which $k_{\min }^{\text {secondary }}$ starts to develop due to the 
connection of micro-fissures), $\sigma_{\perp 2}{ }^{\prime}[\mathrm{MPa}]$ is the effective stress perpendicular to the orientation of the micro-fissures, $\mathrm{Ei}(x)$ is the exponential integral function and $k^{*}=1 \mathrm{~m}^{2}$. Parameters $d, e$ and $f$ are salt-specific. Note that the permeability recovery due to healing (dilatancy decrease) can be modelled using Eq. (6).

Secondly, natural salt may be subjected to a fluid infiltration (or percolation) process if the pore pressure locally exceeds the minimum compressive principal stress (Popp and Minkley, 2010; Wolters et al., 2010). Such a scenario is feasible in a repository for heat-generating nuclear waste in rock salt given the thermal pressurization of fluids within the very-low permeability host rock and the convergence-induced pore pressure increase. Gas generation from the waste packages may also trigger fluid permeation within the host rock. The study of fluid infiltration has led to the formulation of experimentally-determined relationships for the induced secondary permeability. In this study, we use

$$
k_{\text {salt }}^{\text {secondary }}=10^{i_{1}+i_{2} \arctan \left(i_{3} \Delta P_{F l}\right)+i_{4} \exp \left(i_{5} \Delta P_{F l}\right)} k^{*}
$$

where $\Delta P_{F}=\sigma_{3}+P\left[\mathrm{MPa}\right.$ ] ( $\sigma_{3}$ is the minimum compressive principal stress and $P$ is the pore pressure), $k^{*}=1 \mathrm{~m}^{2}$ and $i_{1}, i_{2}, i_{3}, i_{4}$ and $i_{5}$ are salt-specific parameters (Wolters et al., 2012). Note that Eq. (7) is only used to compute a permeability increase if $\Delta P_{F \mid} \geq 0$. Several studies (Fokker, 1995; Kenter et al., 1990; Popp and Minkley, 2010) show that for macro-fractures to develop (hydraulically induced damage), $\Delta P_{F \mid} \approx 2-4 \mathrm{MPa}$ (below this value, opening of grain boundaries and/or micro-fractures occur). Experimental results show that fluid infiltration occurs without necessarily exceeding the dilatancy boundary (Popp et al., 2012; Wolters et al., 2012). An infiltration test conducted at Clausthal University of Technology (Wolters et al., 2012) has been modelled using TOUGH-FLAC and the simulation results have been compared with experimental data. The test was conducted on a cylindrical rock salt sample from a German salt mine. The sample was $350 \mathrm{~mm}$ long, had a diameter of $150 \mathrm{~mm}$ and was initially unsaturated. A $100 \mathrm{~mm}$ long and $50 \mathrm{~mm}$ diameter borehole was drilled along the core axis, see Fig. 2a. A fluid 
containing a fluorescent tracer was injected through the borehole, while the upper and lateral surfaces of the sample were no-flow boundaries (the downstream boundary was kept at atmospheric pressure). The test lasted 6 days and was held at room temperature (about $\left.25^{\circ} \mathrm{C}\right)$ in a triaxial cell, with an axial stress of $20.5 \mathrm{MPa}$ and a confining pressure of $20 \mathrm{MPa}$. The fluid was injected in the borehole at a constant pressure of $21 \mathrm{MPa}$. After the test, the rock salt sample was sliced axially and put under ultraviolet light; this caused the tracer in the injected fluid to fluoresce. The delimited area in Fig. 2a represents the extension of the fluorescent, infiltrated area within the rock salt sample. Fig. $2 \mathrm{~b}$ displays the predicted infiltrated area at the end of the test (i.e., the area in which $\Delta P_{F} \geq 0$ ). In this area, the sample is saturated. It can be inferred from the two images in Fig. 2 that the numerical prediction is similar to the experimental results. The TOUGH-FLAC run was carried out in axisymmetric conditions. The initial permeability of the salt sample was $10^{-22} \mathrm{~m}^{2}$ and Eq. (7) was used in the grid blocks verifying the condition $\Delta P_{F} \geq 0$. Corey's relative permeability curves were used with zero residual liquid and gas saturations. The porosity of the sample was approximated to $0.5 \%$ based on the volume of fluid injected and the delimited area in Fig. 2a. Capillary effects were disregarded.

The solid line in Fig. 3 represents the modelled volume of fluid injected into the rock sample, while the points correspond to the volume of fluid injected during the experiment (these data are calculated subtracting the borehole volume from the raw values of injected volume). Note that the numerical prediction accounts for the borehole compressibility; this compressibility might explain the sharp increase in the volume injected at the beginning of the test. As the figure shows, the experimental and simulated injected volumes are in good agreement.

\subsection{Thermal, hydraulic and mechanical characteristics of the crushed salt}

The reconsolidation process of the crushed salt is modelled using a modified version of the cwipp model available in FLAC ${ }^{3 \mathrm{D}}$. The cwipp model is based on previous studies on crushed 
salt compaction (Callahan and DeVries, 1991; Sjaardema and Krieg, 1987) and on the wipp model for natural salt, also implemented in FLAC ${ }^{3 D}$ (Itasca, 2009).

The main characteristic of the cwipp model is that it allows modelling time-dependent volumetric strain changes (classically, viscoplasticity occurs at constant volume). The total strain rate

tensor, $\varepsilon_{i j}$, comprises a nonlinear elastic component, a viscous compaction component and a viscous shear contribution. The latter is adapted from the wipp model and is purely deviatoric. The total strain rate tensor reads

$\varepsilon_{i j}=\varepsilon_{i j}^{e}+\varepsilon_{i j}^{v c}+\varepsilon_{i j}^{v s}$

where superscripts $e, v c$ and $v s$ stand for elastic, viscous compaction and viscous shear, respectively. As reconsolidation occurs, density increases towards that of the natural salt. While density is not allowed to decrease in the cwipp model, it honors the volumetric strain evolution in our modified version. The nonlinear density rate is derived from experimental results. The viscous compaction term in the model accounts for the density evolution. This term is only active if the mean effective stress is compressive and if the monotonic density has not yet reached the intact salt density (i.e., there is no further compaction beyond the density of intact salt). During compaction, the elastic parameters (shear, $G$, and bulk, $K$, moduli) increase as the monotonic density increases according to a nonlinear empirical expression of the form $a=a_{\text {salt }} \exp \left(a_{1}\left[\rho-\rho_{\text {salt }}\right]\right)$

where $a=\{K, G\}$. Variables $\rho$ and $\rho_{\text {salt }}$ stand for the drained densities of the crushed salt and the natural salt, respectively (drained density is defined as rock mass divided by total volume). Parameter $a_{1}\left[\mathrm{~kg}^{-1} \cdot \mathrm{m}^{3}\right]$ is obtained from the condition that the moduli take their initial values at the initial value of density. According to the model defined in Eq. (9), when $\rho=\rho_{\text {salt }}$ the elastic moduli are those of the natural salt. However, it is important to highlight that experimental data sets at realistic load conditions do not cover the porosity range below 5-10 \% (DBE, 2001; 
Kröhn et al., 2012). Therefore, some uncertainties exist about the accuracy of the cwipp model in that range.

In total, the cwipp model is characterized by 17 parameters. Note that as the bulk modulus increases towards that of the intact salt, the Biot coefficient decreases from almost 1 to the Biot coefficient of the host rock. In this study, we calculate the Biot coefficient using the classical definition (Coussy, 1995)

$\alpha_{\text {crushed salt }}=1-\frac{K}{K_{s}}$

where $K$ is the drained bulk modulus and $K_{s}$ is the bulk modulus of the solid material.

It should be noted that the long-term mechanical responses predicted by the cwipp and the Lux/Wolters models are similar: due to the creep over time, the stresses tend toward the isotropic state and therefore the deviatoric components of both models tend to zero; for the crushed salt, the compaction component vanishes after full reconsolidation, and for the natural salt, damage and healing counteract each other. Consequently, only the elastic components prevail, see Eqs. (2) and (8). Given that after reconsolidation the elastic moduli of the crushed salt are equal to those of the natural salt, the modelled long-term responses of the two materials are similar.

As for the flow properties of the crushed salt, experimental investigations suggest that not only the porosity, but also the permeability, the specific heat and the thermal conductivity evolve as reconsolidation occurs (Bechthold et al., 2004). After full reconsolidation, these properties reach the characteristic values of the natural salt; however, their evolution is uncertain because scarce data exist for low porosities (<5-10\%). In this research, the permeability decrease is calculated using

$$
k_{\text {crushedsalt }}=5.6810^{-11} \phi^{4.36}
$$


where $\phi[-]$ is the current porosity and $k_{\text {crushed salt }}\left[\mathrm{m}^{2}\right]$. We note that we developed Eq. (11) as an approximation to available porosity data in the range $1.5-40 \%$. The grain specific heat dependence on temperature is similar to that of the natural salt (Eq. (4)). The thermal conductivity increases nonlinearly as porosity decreases according to

$\lambda_{\text {crushedsalt }}=-270 \phi^{4}+370 \phi^{3}-136 \phi^{2}+1.5 \phi+5$

where $\phi[-]$ is the current porosity and $\lambda_{\text {crushed salt }}\left[\mathrm{W} \cdot \mathrm{m}^{-1} \cdot \mathrm{K}^{-1}\right]$ (Bechthold et al., 2004).

Finally, regarding the damage processes that could affect the flow properties of the crushed salt, fluid infiltration may take place after reconsolidation if $\Delta P_{F} \geq 0$. In that case, we calculate the permeability increase using Eq. (7).

\section{Long-term prediction of a generic salt repository for heat-generating nuclear waste}

\subsection{Model description}

We simulate a generic salt repository, i.e., without reference to a particular disposal program. We assume that the waste packages are emplaced parallel to the drift axis. Our model extends $1200 \mathrm{~m}$ in the vertical direction ( $Z$ axis) and starts at the ground surface $(Z=0)$. The repository is located in the middle of a $400 \mathrm{~m}$ thick salt layer, at a depth of $600 \mathrm{~m}$. Two $400 \mathrm{~m}$ thick sandstone layers confine the salt seam. The drifts are $4.5 \mathrm{~m}$ wide and $3.5 \mathrm{~m}$ high. The cylindrical metallic waste packages are $5.5 \mathrm{~m}$ long, have a diameter of $1.6 \mathrm{~m}$ and are separated by $3 \mathrm{~m}$ along the drift axis.

At this initial stage of the research, we use a two-dimensional plane-strain assumption. Symmetry allows modelling just half of one drift. In the $X$ direction, drifts are $50 \mathrm{~m}$ apart. The model geometry is presented in Fig. 4, with an enlarged view of the area near the drift. We acknowledge that more accurate predictions would be obtained in a three-dimensional configuration, including the space between waste packages (i.e., drift cross-sections containing only crushed salt). In a two-dimensional case, temperatures are slightly over-predicted, causing faster drift closure and consequently faster backfill reconsolidation. In the future, once further 
improvements are made into the simulator, in particular as regards computational efficiency, we intend to perform full 3D simulations.

Along with the mechanical response, two-phase flow of water and air (by advection and diffusion) and heat flow (by conduction and convection) are modelled. TOUGH2 Equation Of State (EOS) module 4 is used (Pruess et al., 2011). This module provides a capability for vapor pressure lowering, which allows a liquid phase to exist when the vapor partial pressure and the gas phase pressure are lower than the saturation pressure (due to phase adsorption and capillary effects). Vapor pressure lowering is modelled via Kelvin's equation (Pruess et al., 2011).

The heat released by each waste package is consistent with the expected nuclear waste characteristics in the US Department of Energy Used Fuel Disposition Campaign (Carter et al., 2011b). It is assumed that each waste package comprises ten pressurized water reactor (PWR) assemblies and that the packages are emplaced underground after 20 years of interim storage. Under these conditions, and taking the size and distance between canisters into account, the average heat load per meter of drift is approximately $1000 \mathrm{~W}$ at the time of emplacement. The heat load evolution after emplacement is displayed in Fig. 5 (note that the time is reset to zero when the waste packages are emplaced underground).

\subsection{THM properties, initial and boundary conditions}

Table 1 lists parameters used for the crushed salt, the host rock and the confining layers. Some of these parameters have been adopted from previous research (Bechthold et al., 2004;

Camphouse et al., 2012; Jové-Colón et al., 2012; Olivella et al., 2011). We highlight that, in the absence of sufficient experimental data on capillary effects in natural halite, we have used an extrapolation of capillary pressure data corresponding to granular salt (Olivella et al., 2011), using a Leverett factor (Cinar et al., 2006; Leverett, 1941). The van Genuchten function (van 
Genuchten, 1980) is used for all materials. Temperature and hysteresis effects on water retention are neglected.

From a mechanical viewpoint, the waste package and the confining layers are assumed to behave elastically. The Lux/Wolters model parameters used for the host rock have been obtained from the interpretation of experimental results (Lerche, 2012). Regarding the cwipp model for the crushed salt, the values used have been adapted from available experimental data (DBE, 2001; Itasca, 2009). We reiterate that experimental data for porosities smaller than 5-10\% are scarce; therefore, some uncertainties exist about the validity of the parameters used.

For the waste package, we assume $\rho=7800 \mathrm{~kg} \cdot \mathrm{m}^{-3}, \alpha=1, k=0 \mathrm{~m}^{2}$ and $\phi=0.01 \%$. Its pores are saturated with gas, and capillary effects are disregarded because no phase changes are expected. Elastic properties correspond to standard steel.

The flow properties of the natural salt and the crushed salt evolve as described in sections 2.2 and 2.3 respectively. We note that capillary forces are scaled during the simulations as porosity and permeability evolve (Leverett, 1941). On the other hand, properties of the waste package and the confining layers are kept constant during the simulations: the waste package is only modelled to account for the heat release into the repository, and the confining layers are far from the drift, so they are hardly influenced by the THM processes occurring in the drift area. The molecular diffusion coefficients depend on pressure and temperature (Vargaftik, 1975; Walker et al., 1981). Tortuosity effects are accounted for using the Millington-Quirk model (Millington and Quirk, 1961).

Initial flow parameters are listed in Table 2. The absolute permeability $k$ is assumed isotropic for every material.

A geothermal gradient of $0.025 \mathrm{~K} \cdot \mathrm{m}^{-1}$ is initially applied to the model. This corresponds to about $28{ }^{\circ} \mathrm{C}$ at the repository level assuming a ground surface temperature of $10 \stackrel{\circ}{ } \mathrm{C}$. The initial 
mechanical condition is isotropic stress, equal to the lithostatic stress magnitude (overburden); this corresponds to about $-14 \mathrm{MPa}$ at $Z=-600 \mathrm{~m}$. For the calculation of the pore pressure, we assume that the water table is at the ground surface. Regarding the fluid inclusions at the boundaries of natural salt crystals, we assume an initial liquid saturation of $100 \%$. Prior to the THM run, the excavation, subsequent emplacement of the waste packages and drift backfilling are modelled in $\mathrm{FLAC}^{3 \mathrm{D}}$ to account for the induced stress redistribution and possible changes in the pore pressure. The pore pressure obtained after the excavation is exported to TOUGH2, so that the initial conditions of the THM run are the same in the two codes (the coupled THM simulation covers the post-closure phase of the repository, once the heat-generating waste packages are emplaced and the drifts backfilled). Note that the initial pore pressure within the backfill and the waste package is set to $0.1 \mathrm{MPa}$ (atmospheric pressure). At this stage, and according to the fixed stress-split sequential method to couple flow and geomechanics (Kim et al., 2011), the $\mathrm{FLAC}^{3 \mathrm{D}}$ capability to calculate pore pressure is deactivated (i.e., the pore pressure computed by TOUGH2 is used in both codes, see Fig. 1).

In TOUGH2, Dirichlet boundary conditions are assigned to the top and bottom grid blocks, so that their thermodynamic state remains unchanged. Owing to symmetry, the lateral surfaces of the model are no-flow boundaries. In $\mathrm{FLAC}^{3 \mathrm{D}}$, the horizontal displacement is blocked in planes $X=0$ and $X=25 \mathrm{~m}$, as well as the vertical displacement in plane $Z=-1200 \mathrm{~m}$. Gravitational effects are considered in both codes.

\subsection{Base case THM simulation results}

In the 2D simulations presented in this paper, our main goal is to analyze the numerical predictions obtained using the updated version of TOUGH-FLAC, in particular as regards the different processes occurring in the host rock and in the backfill material. We note that the discussions hereafter do not include a comprehensive validation based on measurement data of the physical processes. 


\subsubsection{Preliminary definitions}

The base case scenario is characterized by the use of the equivalent pore pressure in the geomechanics sub-problem. The equivalent pore pressure is defined as

$$
P_{\mathrm{eq}}=\sum_{i=1}^{N P H} P_{i} S_{i}+U
$$

where $P_{i}$ is phase pressure, $S_{i}$ is phase saturation, $U$ is the interfacial energy per unit of pore volume and $\mathrm{NPH}$ is the number of phases present (Coussy, 2004). Neglecting the temperature dependence of capillary forces, the interfacial energy can be determined from the capillary curve according to

$$
U\left(S_{w}\right)=\int_{S_{w}}^{1} P_{\text {cap }}(S) d S
$$

where $P_{\text {cap }}<0$ is the capillary pressure. According to Coussy (2004), the equivalent pore pressure should be used when capillary forces are non-negligible, which is the case of the natural salt and the reconsolidated crushed salt due to their very low porosity $(\phi<1-2 \%)$. In addition, this pressure is the proper definition of multiphase pore pressure because it renders a formulation that is dissipative (Kim et al., 2013).

We note that other common pore pressure concepts adopted in geomechanics when several fluid phases occupy the pores are the maximum phase pressure and the saturation-weighted average fluid pressure (Kim et al., 2013).

\subsubsection{Results}

Fig. 6 displays the temperature evolution at different positions in the repository over the simulated 100000 years of post-closure phase. We stress that these results are dependent on the thermal loading applied (Fig. 5).The temperature at the waste package surface peaks slightly below $200^{\circ} \mathrm{C}$ after about one year. Note that the nearby crushed salt and host rock also show an initial temperature peak. This local peak is due to the low thermal conductivity of the 
backfill before significant compaction takes place (cf. Eq. (12)). After 25 years, a temperature peak of about $160^{\circ} \mathrm{C}$ is obtained in the drift area. The temperature $25 \mathrm{~m}$ away from the drift peaks at about $108^{\circ} \mathrm{C}$ after 80 years, reflecting progressive heat propagation through the natural salt. As compared to other potential host rocks such as clay or granite, and for a given heat load, the peak temperature in a salt-based repository is lower owing to a higher thermal conductivity. A comparatively low peak temperature is a desirable performance indicator for a heat-generating nuclear waste repository.

During the excavation phase, a damaged zone develops in the host rock adjacent to the drift contour due to the high deviatoric stresses in this zone. The thickness of the EDZ is about $1.4 \mathrm{~m}$ at the drift floor and $1 \mathrm{~m}$ at the sidewalls and roof. Shear damage spreads all around the drift, but tensile damage mostly occurs in the corner area, due to the shape of the drift (see the enlarged view in Fig. 4). While after 4 years shear dilatancy peaks at about $1.2 \%$, tensile dilatancy reaches $2.6 \%$ (but remains localized in the corner). As a consequence of damage, Eq. (6) predicts a permeability increase up to four-five orders of magnitude in the EDZ; however, a permeability of $10^{-18}-10^{-17} \mathrm{~m}^{2}$ is still characteristic of an impervious material (Bérest et al., 2005; Cosenza, 1996). Porosity also increases, but remains very low ( $\left.\phi_{\max }<1.3 \%\right)$. As permeability and porosity increase, capillary forces weaken. Moreover, the Biot coefficient increases according to Eq. (3) up to 0.8 in the most damaged areas, thereby intensifying the poromechanical effects.

As the salt creeps under the effect of temperature and deviatoric stresses, the reconsolidation of the crushed salt starts. Our results suggest that the reconsolidation process is not uniform in space, due mainly to the shape of the drift and the position of the heat source (the waste package acts as a rigid inclusion, resisting movement of the backfill above it, and increasing the local stress): greater compaction occurs in the roof and floor areas, and smaller in the sidewalls. These results agree with previous numerical investigations (Stone et al., 2010). Overall, in the 
scenario that we study, the backfill reconsolidation process takes between 6 and 20 years to complete. Fig. 7 displays the evolution of porosity at three crushed salt locations during the first 20 years after emplacement. When the crushed salt is reconsolidated, porosity has reached the characteristic value of the undisturbed salt. The predicted duration of the reconsolidation process may be too short and we highlight that it is uncertain for now. Therefore, these results are not conclusive. As more reconsolidation data at relevant loading conditions and temperatures become available, these predictions may change. In any case, we note that the new formulation implemented in TOUGH-FLAC to compute porosity changes successfully allows us to model mechanical compaction, and that the geomechanical component dominates over the pressure- and temperature-related components in the computation of porosity changes (this stresses the pertinence of the new version of TOUGH-FLAC). As the crushed salt reconsolidates, its permeability reduces by up to nine orders of magnitude according to Eq. (11), and its thermal conductivity increases following Eq. (12), from about 1 to $4-5 \mathrm{~W} \cdot \mathrm{m}^{-1} \mathrm{~K}^{-1}$. At the same time, the elastic moduli increase towards those of the natural salt (two-orders-ofmagnitude increase, cf. Eq. (9)); as a result, the Biot coefficient decreases towards the characteristic value of the undisturbed natural salt ( 0.003) according to Eq. (10). Note also that capillary forces become stronger as porosity and permeability decrease (Cinar et al., 2006; Leverett, 1941). A geotechnical barrier system is progressively created during the reconsolidation process.

As the crushed salt strengthens, an internal support is provided at the drift walls, which helps decrease the deviatoric stresses. The stress state in the drift area progressively evolves towards isotropic (thus, away from the dilatancy boundary). The occurrence of healing is closely related to the backfill compaction, which confirms the strong two-way interaction between the host rock and the backfill THM evolution. After about 6 years, healing has significantly reduced damage and dilatancy, and, after 7 years, dilatancy verifies $\varepsilon_{v o l} \approx \varepsilon_{v o l, 0}$. According to Eq. (6), in 
the current scenario the initial tightness of the host rock is restored after about 7 years. The three images in Fig. 8 compare the extension of the EDZ at three moments: after excavation, after 4 years and after 7 years. While the damaged area increases during the first years, it decreases until vanishing once healing starts.

As temperature increases overall after about 5 years, the pore pressure increases too. In the natural salt, the very low permeability, saturated conditions and high thermal expansion coefficient of the pore fluid relative to the host rock are key factors for this thermal pressurization. Concerning the crushed salt backfill, the compaction-induced volume reduction facilitates resaturation and a significant pore pressure increase. Fig. 9a shows the evolution of pore pressure (equivalent pore pressure as defined in Eqs. (13-14)) and Fig. 9b displays the evolution of liquid saturation at five different positions in the repository: three locations in the host rock and two locations in the crushed salt. As the backfill liquid saturation increases steeply just before 10 years, the pore pressure increases in a similar fashion. Additionally, as the backfill saturation increases the pore pressure is the same at the five locations monitored, see Fig. 9a. The equivalent pore pressure peaks below $16 \mathrm{MPa}$. According to Eq. (7), $\Delta P_{f} \approx 1-2 \mathrm{MPa}$; this results in fluid infiltration into the rock mass through the opening of grain boundaries and/or micro-fractures (Fokker, 1995; Kenter et al., 1990; Popp and Minkley, 2010). Indeed, pore pressure cannot increase much above the infiltration criterion because infiltration will work against further pore pressure increase, and it cannot decrease below the infiltration criterion because the infiltration-induced grain boundary openings and/or micro-fractures will close again, triggering a new pore pressure increase, which will result in infiltration. In the current scenario, the main cause to fluid permeation is the thermal pressurization of the liquid phase induced by the time-dependent release of decay heat from the waste packages. As the heat load and temperature decrease over time (see Figs. 5 and 6), pore pressure and infiltration reduce progressively (see Fig. 9a), and the initial permeability of the host rock is restored. As compared 
to a previous study (Blanco Martín et al., 2014), in this case the maximum pore pressure reached is lower because the secondary permeability increases beyond $10^{-20} \mathrm{~m}^{2}$ during fluid infiltration.

The analysis of the results shows that fluid permeation into the rock starts after 6 years at a location $8 \mathrm{~m}$ away from the drift along the $X$ axis. Permeation does not start in the drift area because the pore pressure is smaller in this zone due to the partial desaturation of the near-field host rock in the first years of the post-closure phase, see Fig. 9 (the first temperature peak and the porosity increase trigger this partial desaturation). After 10-20 years, the pressure is uniform in the backfill and near-field host rock and pressure-driven fluid infiltration occurs. The area that undergoes infiltration is significantly larger than the area affected by thermo-mechanical damage (EDZ); it extends at the repository-level along the $X$ and $Z$ axis as pressure increases (thermal pressurization), but it does not reach the confining layers (the extension along the $\mathbf{Z}$ axis is about $100 \mathrm{~m}$ above and below the drift). The reconsolidated backfill also undergoes infiltration if $\Delta P_{F} \geq 0$.

Finally, in Fig. 9, the pressure and saturation drop that occurs after 10000 years is due to a thermal depressurization at the repository-level (compare simultaneous temperature and pressure drops in Figs. 6 and 9). After 100000 years, once the heat load released by the waste packages tends to zero, the initial temperature and pore pressure are restored.

\subsection{Comparison of TH and THM results}

A thermal-hydraulic simulation (without the mechanical component) has been conducted to determine how relevant the coupling to mechanical processes is to evaluate the natural salt and crushed salt over time. Such a determination helps analyze the usefulness of the updated TOUGH-FLAC simulator to perform the target predictions.

Fig. 10 displays the temperature evolution at the same locations as in Fig. 6. The temperature at the waste package peaks at $267^{\circ} \mathrm{C}$ after 10 years. As the figure shows, only one 
temperature peak is obtained. Indeed, if the mechanical effect is not accounted for, the backfill porosity hardly changes and therefore the thermal conductivity of this material remains low, cf. Table 2 and Eq. (12). The low thermal conductivity of the crushed salt explains the higher temperatures; the nearly constant value of this property explains that only one temperature peak is obtained. As in the THM case, the temperature $25 \mathrm{~m}$ away from the drift peaks at around $108^{\circ} \mathrm{C}$ after 80 years.

In Fig. 11, the evolution of pore pressure and liquid saturation is given at the same locations as in Fig. 9. If the mechanical component is neglected, the far field pressure peaks above $37 \mathrm{MPa}$ after 27 years. This pressure is significantly higher than the one obtained in the THM run, $P_{\max } \approx 16 \mathrm{MPa}$ (see Fig. 9a). In the TH run, neither thermo-mechanical damage nor fluid infiltration is accounted for and as a result the permeability of the natural salt remains constant at its initial value, which explains the higher pressures reached. In the drift area, the pore pressure remains low: in the backfill, $P<1 \mathrm{MPa}$ and in the host rock, $P<1-2 \mathrm{MPa}$. Note that since the crushed salt porosity barely changes, $k=3 \cdot 10^{-13} \mathrm{~m}^{2}$, which is a very high value in the context of a nuclear waste repository. Also, the very low permeability of the host rock and its strong capillary forces delay the flow towards the drift in the long-term. The TH simulation captures the pressure decrease below the hydrostatic level after 10000 years. The initial pressure is not recovered in the area under investigation after 100000 years, see Fig. 11a. As compared to Fig. 9b, the liquid saturation evolution displayed in Fig. 11b is also quite different: in the host rock around the drift, liquid saturation does not change noticeably because porosity and permeability remain very low. Because of the absence of compaction, the backfill saturation does not increase steeply as shown in Fig. 9b. In fact, the backfill resaturation is not complete after 100000 years (the initial saturation was very low, $1.5 \%$, and the mass flow from the host rock is very small due to the near-zero permeability [maximum flow rates are about $10^{-}$ $\left.\left.{ }^{9} \mathrm{~kg} \cdot \mathrm{m}^{-2} \cdot \mathrm{s}^{-1}\right]\right)$. The liquid phase in the crushed salt progressively flows by gravity towards the 
drift floor, so that after 100000 years only the crushed salt in the floor area is saturated (note that capillary forces within the unconsolidated crushed salt are weak).

From these results, it can be concluded that $\mathrm{TH}$ simulations cannot capture key aspects such as backfill resaturation or temperature and pore pressure evolution. Furthermore, the backfill barrier development cannot be evaluated without accounting for the mechanical effects.

Additionally, a realistic analysis of the natural salt barrier cannot be conducted if infiltration, damage and healing processes, which have been observed in the field and in the laboratory, are disregarded. Therefore, the coupling to mechanical processes is needed. This supports the development of the updated version of TOUGH-FLAC, which also allows HM and TM analyses.

\subsection{Sensitivity of the THM predictions}

In this section, we investigate the sensitivity of the THM simulation results to two factors: the initial saturation within the host rock and the capillary forces.

\subsubsection{Initial saturation of the host rock}

A THM simulation in which the host rock has an initial saturation of $50 \%$ has been performed. Intercrystalline brine has been observed in salt samples (Desbois et al., 2012; Jové-Colón et al., 2012) and justifies the assumption of initial fully saturated conditions in the host rock. However, it is considered important to analyze the effects of a possible lower initial saturation on the long-term predictions.

The temperature evolution obtained is similar to that of the base case scenario, displayed in Fig. 6. In the first years, damage and dilatancy develop as well, although after 4 years the values are slightly lower than in the base case, mainly because the equivalent pore pressure is lower in the current scenario (cf. Eqs. (13-14)). Dilatancy does not exceed $2.6 \%$ in this case. Its temporal evolution and spatial distribution are very similar to the base case scenario (Fig. 8). The crushed salt reconsolidation process and barrier development occur in a similar way. After 7 years, the EDZ is sealed and the initial tightness of the host rock restored. 
The most important differences as compared to the reference case are related to the evolution of pore pressure and liquid saturation, which are displayed in Fig. 12, at the same locations as in Fig. 9. Regarding the pore pressure, a peak of about $15 \mathrm{MPa}$ occurs after approximately 10 years. Therefore, the maximum pressure reached is similar to the maximum pressure in the base case (rock salt fully saturated); however, its temporal and spatial distributions are very different (compare Figs. 9a and 12a). In this case, fluid infiltration only occurs between 9 and 20 years due to the high compressibility of the gas phase (liquid saturation is $50 \%$ ), which can accommodate the fluid thermal expansion. Because of this reduced thermal pressurization, the area affected by infiltration is very small, and does not spread farther than $1.5 \mathrm{~m}$ from the drift contour. After 20 years, the sealing capacity of the host rock is fully restored and the pressure decreases following the temperature decrease. Moreover, as Fig. 12a shows, the location $25 \mathrm{~m}$ away from the drift is not affected by the pressure increase. We also note that as the effect of the heat loading reduces, the pore pressure is the same in the five locations monitored.

The saturation curves shown in Fig. 9b are also quite different (recall that in the current case the initial saturation is $50 \%$ ), although the processes involved are similar: in the first years, the temperature increase causes vaporization in the crushed salt and adjacent host rock, and the steam condenses subsequently following the temperature evolution. As the figure shows, backfill compaction also brings about a steep increase in liquid saturation after 10 years. The saturation at the location $25 \mathrm{~m}$ away from the drift remains unchanged.

From these results, it can be concluded that the most important effect of the initial saturation within the host rock is related to the temporal and spatial extent of fluid permeation: for a given heat loading, the higher the saturation, the higher the extent (compare Figs. 9a and 12a). This shows the importance of correctly assessing the initial conditions within the host rock.

\subsubsection{Capillary forces}

Capillary forces within natural salt are difficult to quantify and because of this, scarce 
experimental data are available (Kuhlman, 2014). In order to get a sense of how important capillarity effects are in the long-term predictions, we performed a coupled THM simulation in which we did not use water retention curves. When capillary forces are disregarded, the gas and liquid pressures are identical and equal to the equivalent pore pressure, defined in Eqs. (13-14).

As compared to the base case scenario, the most important differences when capillary effects are neglected are found in partially saturated areas. Given that for $S_{k}$ the pore pressure is higher in the current case, damage and dilatancy in the EDZ are slightly higher (same extension and evolution as in Fig. 8, but maximum dilatancy gets to $2.67 \%$ ). Like in the base case scenario, the EDZ is sealed after 7 years and the backfill is reconsolidated after 20 years. Fig. 13 displays the pore pressure and liquid saturation evolution at the same locations as in Fig. 9. As the figure shows, pore pressure trends are very similar, with a maximum value of about $16 \mathrm{MPa}$ and fluid infiltration occurring while $\Delta P_{f f} \geq 0$. Regarding liquid saturation, it reduces to lower values at the drift contour when temperature peaks initially (compare corresponding locations in Figs. 9b and 13b).

On the other hand, in the long-term the saturation profile in the host rock around the drift is quite different: the lack of capillary forces promotes gravity-dictated mass flow in the long-term (although very small); as a result, some desaturation occurs above the drift. Fig. 14 compares the liquid saturation profile after 100000 years in two situations: when capillary forces are considered (base case scenario) or neglected (current case). As the figure shows, when capillary forces are neglected the host rock above the drift is not completely saturated owing to the downwards flow.

To conclude, if capillary forces are disregarded, the most important effect is found in the natural salt above the drift, where some desaturation occurs over the long-term as water flows slowly by 
gravity. In terms of thermo-mechanically induced damage and fluid infiltration within the formation, no significant differences have been observed.

\section{Conclusions}

The sequential TOUGH-FLAC simulator for coupled THM processes in porous media has recently been provided with a capability for large strains and creep behavior. This update has been required in order to investigate the long-term response of a generic salt repository for heat-generating nuclear waste with crushed salt backfill.

The updated TOUGH-FLAC includes state-of-the-art constitutive relationships that provide a phenomenological description of relevant processes within the natural salt and the crushed salt backfill. Theoretical and material-specific experimental studies have been accounted for in the coupling of the geomechanics and flow simulators. Using the updated version of TOUGH-FLAC, current knowledge about the compaction of the backfill and subsequent evolution of its properties towards those of the natural salt can be modelled. Several processes that are known to influence the initial tightness of the host rock can also be investigated.

The simulations presented in this paper comprise the stages of excavation, waste emplacement, backfilling and a post-closure period of 100000 years. Important performance indicators of a nuclear waste repository are examined, such as peak temperature and fluid pressure, EDZ evolution and time for backfill reconsolidation. Overall, the simulation results suggest that the EDZ is healed within the first few years. On the other hand, uncertainties remain regarding the backfill compaction, as available data at relevant loading and temperature conditions are scarce, and therefore current models cannot be fully validated against experimental data and may overestimate the time required for full reconsolidation, which is unknown so far. Depending on the magnitude of the pore pressure relative to the minimum compressive principal stress, fluid infiltration and secondary permeability may occur at a larger 
temporal and spatial scale. Once damage processes are over, our predictions show that the initial tightness of the host rock is restored.

The comparison of coupled THM simulation results with those obtained when the mechanical processes are disregarded reflects the importance of accounting for the latter and supports the development of the updated TOUGH-FLAC simulator (for TM, HM and THM analyses). Indeed, if the mechanical component is omitted, the temperature and the pore pressure evolution cannot be correctly captured. Most importantly, the backfill reconsolidation and the barrier development cannot be investigated if the coupling to mechanical processes is neglected. We have also investigated the sensitivity of the predictions to features that are more difficult to assess. Our results show that the initial saturation within the natural salt has a significant impact on the simulation results, in particular as regards fluid infiltration, and that capillary effects should be properly included for more realistic long-term predictions.

Although the simulation results presented are preliminary, the numerical tools needed to investigate coupled processes in saliferous media have been considerably improved. In future work, we intend to account for gas generation from the waste packages (due to corrosion), and we will include the effects of brine dissolution and precipitation in the coupling scheme (halite solubility constraints). Moreover, a three-dimensional simulation of an emplacement drift will allow us to analyze the evolution of the displacement field, including thermally-induced uplift.

\section{Acknowledgements}

The authors gratefully acknowledge Stefan Finsterle and Víctor Vilarrasa for their careful review of a draft manuscript. The cooperation with Prof. Lux's team at the Department of Waste Disposal and Geomechanics, Clausthal University of Technology, is kindly appreciated. The constructive comments issued from the anonymous review process have significantly improved the quality of this paper. Funding for this work has been provided by the Used Fuel Disposition 
Campaign, Office of Nuclear Energy of the U.S. Department of Energy, under Contract Number DE-AC02-05CH11231 with Lawrence Berkeley National Laboratory.

\section{References}

Argüello, J.G., Rath, J.S., 2012. SIERRA mechanics for coupled multi-physics modeling of salt repositories. In: Bérest, P., Ghoreychi, M., Hadj-Hassen, F., Tijani, M. (Eds.), Proc. $7^{\text {th }}$ Int. Conf. Mech. Behav. Salt (SaltMech7), Paris, France, pp. 405-415.

Argüello, J.G., Rath, J.S., 2013. Revisiting the 1980's WIPP Room D and B in-situ experiments: performing thermo-mechanical simulations of rock salt using a state-of-the art code suite. In: Proc. $47^{\text {th }}$ US Rock Mech./Geomech. Symp., San Francisco, CA, USA, pap. ARMA 13-370 (on CD-ROM).

Bathe, K.-J., Ramm, E., Wilson, E.L., 1975. Finite element formulations for large deformation dynamic analysis. Int. J. Numer. Methods Eng. 9(2), 353-386. doi: 10.1002/nme.1620090207.

Bechthold, W., Rothfuchs, T., Poley, A., Ghoreychi, M., Heusermann, S., Gens, A., Olivella, S., 1999. Backfilling and Sealing of Underground Repositories for Radioactive Waste in Salt (BAMBUS Proj.). Eur. Atomic Energy Community. Rep. EUR19124 EN, 283 pp.

Bechthold, W., Smailos, E., Heusermann, S., Bollingerfehr, W., Bazargan Sabet, B., Rothfuchs, T., Kamlot, P., Grupa, J., Olivella, S., Hansen, F.D., 2004. Backfilling and Sealing of Underground Repositories for Radioactive Waste in Salt (BAMBUS II Proj.). Eur. Atomic Energy Community. Rep. EUR20621 EN, 305 pp.

Bérest, P., Brouard, B., Karimi-Jafari, M., 2005. Deep salt caverns abandonment. In: Proc. PostMin. Symp., Nancy, France, 12 pp.

Blanco Martín, L., Rutqvist, J., Birkholzer, J.T., 2013. Long-term analysis of thermal-hydraulicalmechanical processes in a generic salt repository for high-level nuclear waste. In: Proc. 
$48^{\text {th }}$ US Rock Mech./Geomech. Symp., Minneapolis, MN, USA, pap. ARMA 14-7206 (on CD-ROM).

Callahan, G.D., DeVries, K.L., 1991. Analyses of Backfilled Transuranic Waste Disposal Rooms. RE/SPEC Inc. (Prep. for Sandia Natl. Labs.), Rapid City, SD, USA. Rep. SAND91-7052, $128 \mathrm{pp}$.

Callahan, G.D., Mellegard, K.D., Hansen, F.D., 1998. Constitutive Behavior of Reconsolidating Crushed Salt. RE/SPEC Inc. (Prep. for US DOE), Rapid City, SD, USA. Rep. SAND-980179C, $15 \mathrm{pp}$.

Camphouse, R.C., Gross, M., Herrick, C.G., Kicker, D.C., Thompson, B., 2012. Recommendations and Justifications of Parameter Values for the Run-of-Mine Salt Panel Closure System Design Modeled in the PCS-2012 PA. Sandia Natl. Labs., Albuquerque, NM, USA. Final memo 5412, 28 pp.

Carter, J.T., Hansen, F.D., Kehrman, R., Hayes, T., 2011a. A Generic Salt Repository for Disposal of Waste from a Spent Nuclear Fuel Recycle Facility. Savannah River Natl. Lab. (Prep. for US DOE), Aiken, SC, USA. Rep. SRNL-RP-2011-00149 Rev. 0, 123 pp.

Carter, J.T., Luptak, A.J., Gastelum, J., Stockman, C., Miller, A., 2011b. Fuel Cycle Potential Waste Inventory for Disposition. Prep. for US DOE Used Nucl. Fuel. Rep. FCR\&DUSED-2010-000031 Rev. 5, 328 pp.

Chan, K.S., Bodner, S.R., Fossum, A.F., Munson, D.E., 1997. A damage mechanics treatment of creep failure in rock salt. Int. J. Damage Mech. 6(2), 121-152. doi: $10.1177 / 105678959700600201$.

Cinar, Y., Pusch, G., Reitenbach, V., 2006. Petrophysical and Capillary Properties of Compacted Salt. Transp. Porous Med. 64, 199-228. doi: 10.1007/s11242-005-2848-1.

Clayton, D.J., Argüello Jr., J.G., Hardin, E.L., Hansen, F.D., Bean, J.E., 2012. Thermalmechanical modeling of a generic high-level waste salt repository. In: Bérest, P., 
Ghoreychi, M., Hadj-Hassen, F., Tijani, M. (Eds.), Proc. $7^{\text {th }}$ Int. Conf. Mech. Behav. Salt (SaltMech7), Paris, France, pp. 427-432.

Cosenza, Ph. Sur les couplages entre comportement mécanique et processus de transfert de masse dans le sel gemme. Ph.D. dissertation, Université Paris 6, Paris, France, 184 pp. Cosenza, Ph., Ghoreychi, M., 1999. Effects of very low permeability on the long-term evolution of a storage cavern in rock salt. Int. J. Rock Mech. Min. Sci. 36(4), 527-533. doi:10.1016/S0148-9062(99)00018-2.Coussy, O., 1995. Mechanics of Porous Continua, $2^{\text {nd }}$ edn. John Wiley and Sons, Chichester, UK, 472 pp.

Coussy, O., 2004. Poromechanics, $1^{\text {st }}$ edn. John Wiley and Sons, Chichester, UK, 312 pp.

Cristescu, N.D., 1993. A general constitutive equation for transient and stationary creep of rock salt. Int. J. Rock Mech. Min. Sci. 30(2), 125-140. doi:10.1016/0148-9062(93)90705-I.

DBE, 2001. Numerische Untersuchungen zum Konvergenzverhalten eines Einzelhohlraumes. DBE Technology GmbH, Peine, Germany. Rep. 22341011, 80 pp.

Dean, R.H., Gai, X., Stone, C.M., Minkoff, S.E., 2006. A comparison of techniques for coupling porous flow and geomechanics. SPE J. 11(1), 132-140. doi: 10.2118/79709-PA.

Department of Energy (DOE)/WIPP, 2002. Waste Isolation Pilot Plant Initial Report for PCB Disposal Authorization. Carlsbad, NM, USA. Rep. DOE/WIPP 02-3196, 45 pp.

Desbois, G., Urai, J.L., Schmatz, J., Zavada, P., de Bresser, H., 2012. The distribution of fluids in natural rock salt to understand deformation mechanisms. In: Bérest, P., Ghoreychi, M., Hadj-Hassen, F., Tijani, M. (Eds.), Proc. $7^{\text {th }}$ Int. Conf. Mech. Behav. Salt (SaltMech7), Paris, France, pp. 3-12.

Felippa, C.A., Park, K.C., 1980. Staggered transient analysis procedures for coupled mechanical systems: formulation. Comput. Methods Appl. Mech. Eng. 24(1), 61-111. doi: 10.1016/0045-7825(80)90040-7. 
Fokker, P.A., 1995. The behaviour of salt and salt caverns. Ph.D. Dissertation, Delft University of Technology, Delft, The Netherlands, $142 \mathrm{pp}$.

GRS, 2001. Untersuchungen zur hydraulisch wirksamen Auflockerungszone um Endlagerbereiche im Salinar in Abhängigkeit vom Hohlraumabstand und Spannungszustand (ALOHA 2). GRS, Koln, Germany. Final Rep. BMBF Res. Proj. 02 E 9118.

Hampel, A., Salzer, K., Günther, R.-M., Minkley, W., Pudewills, A., Leuger, B., Zapf, D., Staudtmeister, K., Rokahr, R., Herchen, K., Wolters, R., Lux, K.-H., 2012. Joint projects on the comparison of constitutive models for the mechanical behavior of rock salt II. Overview of the models and results of 3-D benchmark simulations. In: Bérest, P., Ghoreychi, M., Hadj-Hassen, F., Tijani, M. (Eds.), Proc. $7^{\text {th }}$ Int. Conf. Mech. Behav. Salt (SaltMech7), Paris, France, pp. 227-236.

Hampel, A., Argüello, J.G., Hansen, F.D., Günther, R.M., Salzer, K., Minkley, W., Lux, K.-H., Herchen, K., Düsterloh, U., Pudewills, A., Yildirim, S., Staudtmeister, K., Rokahr, R., Zapf, D., Gährken, A., Missal, C., Stahlmann, J., 2013. Benchmark Calculations of the Thermo-Mechanical Behavior of Rock Salt - Results from a US-German Joint Project. In: Proc. $47^{\text {th }}$ US Rock Mech./Geomech. Symp., San Francisco, CA, USA, pap. ARMA 13-456 (on CD-ROM).

Hansen, F.D., 2008. Disturbed Rock Zone Geomechanics at the Waste Isolation Pilot Plant. Int. J. Geomech. 8(1), 30-38. doi: 10.1061/(ASCE)1532-3641(2008)8:1(30).

Hardin, E., Voegele, M., 2013. Alternative Concepts for Direct Disposal of Dual-Purpose Canisters. Prep. for US DOE Used Fuel Disposition Campaign. Rep. FCRD-UFD-2013000102 Rev. 0, 53 pp. 
Hou, Z., 2002. Geomechanische Planungskonzepte für Untertägige Tragwerke mit Besonderer Berücksichtigung von Gefügeschädigung, Verheilung und Hydromechanischer Kopplung, $1^{\text {st }}$ edn. Papierflieger, Clausthal-Zellerfeld, Germany, 366 pp.

Hou, Z., 2003. Mechanical and hydraulic behaviour of rock salt in the excavation disturbed zone around underground facilities. Int. J. Rock Mech. Min. Sci. 40, 725-738. doi:10.1016/S1365-1609(03)00064-9.

Hou, Z., Lux, K.-H., 1998. Ein neues Stoffmodell für duktile Salzgesteine mit Einbeziehung von Gefügeschädigung und tertiärem Kriechen auf der Grundlage der Continuum-DamageMechanik. Geotechnik 21(3), 259-263.

Hou, Z., Lux., K.-H., Düsterloh, U., 1998. Bruchkriterium und Fließmodell für ductile Salzgesteine bei kurzzeitiger Beanspruchung. Glueckauf-Forschungshefte 59(2), 59-67.

Hou, Z., Lux, K.-H., 1999. A constitutive model for rock salt including structural damages as well as practice-oriented applications. In: Proc. $5^{\text {th }}$ Conf. Mech. Behav. Salt, Bucharest, Romania, pp. 151-169.

Hou, Z., Lux, K.-H., 2000. Ein Schädigungsmodell mit Kriechbruchkriterium für duktile Salzgesteine auf der Grundlage der Continuum-Damage-Mechanik. Bauing. 75(13), 300-307.

Hunsche, U., Hampel, A., 1999. Rock salt - the mechanical properties of the host rock material for a radioactive waste repository. Eng. Geol. 52, 271-291. doi: 10.1016/S00137952(99)00011-3.

Hurtado, L.D., Knowles, M.K., Kelley, V.A., Jones, T.L., Ogintz, J.B., Pfeifle, T.W., 1997. WIPP Shaft Seal System Parameters Recommended to Support Compliance Calculations. Sandia Natl. Labs. Albuquerque, NM, USA. Rep. SAND-97-1287, 136 pp. doi: $10.2172 / 563218$. 
Itasca, 2009. FLAC ${ }^{3 D}$ (Fast Lagrangian Analysis of Continua in 3 Dimensions), Version 4.0. Itasca Consulting Group, Minneapolis, MN, USA, 438 pp.

Javeri, V., Baltes, B., 2008. Three dimensional analyses of combined gas, heat and nuclide transport in a repository considering Thermo-Hydro-Geo-Mechanical Processes. In: Proc. $12^{\text {th }}$ Int. Conf. Int. Assoc. Comput. Methods Advances Geomech. (IACMAG), Goa, India, pp. 1264-1268.

Jeannin, L., Mainguy, M., Masson, R., Vidal-Gilbert, S., 2007. Accelerating the convergence of coupled geomechanical-reservoir simulations. Int. J. Numer. Anal. Methods Geomech. 31(10), 1163-1181. doi: 10.1002/nag.576.

Jha, B., Juanes, R., 2007. A locally conservative finite element framework for the simulation of coupled flow and reservoir geomechanics. Acta Geotech. 2(3), 139-153. doi: 10.1007/s11440-007-0033-0.

Jové-Colón, C., Greathouse, J.A., Teich-McGoldrick, S., Cygan, R.T., Hadgu, T., Bean, J.E., Martínez, M.J., Hopkins, P.L., Argüello, J.G., Hansen, F.D., 2012. Evaluation of Generic EBS Design Concepts and Process Models: Implications to EBS Design Optimization. Sandia Natl. Labs. Albuquerque, NM, USA. Rep. FCRD-USED-2012-000140, 250 pp. Kachanov, L.M., 1986. Introduction to Continuum Damage Mechanics, $1^{\text {st }}$ edn. Martinus Nijhoff Publishers, Dordrecht, The Netherlands, 135 pp.

Kansy, A., 2007. Einfluss des Biot-Parameters auf das hydraulische Verhalten von Steinsalz unter Berücksichtigung des Porendruckes. Ph.D. Dissertation, Technische Universität Clausthal, Clausthal-Zellerfeld, Germany.

Kenter, C.J., Doig, S.J., Rogaar, H.P., Fokker, P.A., Davies, D.R., 1990. Diffusion of brine through rock salt of roof caverns. In: Proc. SMRI Fall Meet., Paris, France, 19 pp. 
Kim, J., Tchelepi, H.A., Juanes, R., 2011. Stability and convergence of sequential methods for coupled flow and geomechanics: Fixed-stress and fixed-strain splits. Comput. Methods Appl. Mech. Eng. 200(13-16), 1591-1606. doi: 10.1016/j.cma.2010.12.022.

Kim, J., Sonnenthal, E.L., Rutqvist, J., 2012. Formulation and sequential numerical algorithms of coupled fluid/heat flow and geomechanics for multiple porosity materials. Int. J. Numer. Methods Eng. 92(5), 425-456. doi: 10.1002/nme.4340.

Kim, J., Tchelepi, H. A., Juanes, R., 2013. Rigorous Coupling of Geomechanics and Multiphase Flow with Strong Capillarity. SPE J. 18(6), 1123-1139. doi:10.2118/141268-PA.

Kock, I., Larue, J., Fischer, H., Frieling, G., Navarro, M., Seher, H., 2013. Results from Oneand Two-Phase Fluid Flow Calculations within the Preliminary Safety Analysis of the Gorleben Site-13310. In: Proc. WM2013 Conf., Phoenix, AZ, USA, 15 pp.

Kröhn, K.P., Zhang, C.L., Wolf, J., Stührenberg, D., Jobmann, M., von Borstel, L., Lerch, C., 2012. The compaction behaviour of salt backfill at low porosities. In: Bérest, P., Ghoreychi, M., Hadj-Hassen, F., Tijani, M. (Eds.), Proc. $7^{\text {th }}$ Int. Conf. Mech. Behav. Salt (SaltMech7), Paris, France, pp. 155-162.

KuhIman, K.L., 2014. Summary Results for Brine Migration Modeling Performed by LANL, LBNL and SNL for the UFD Program. Sandia Natl. Labs. Albuquerque, NM, USA. Rep. FCRDUFD-2014-000071, 250 pp.

Lerch, C., Bollingerfehr, W., Filbert, W., Zhang, Q., 2012. Thermo-mechanical analyses for evaluating a HLW-repository concept. In: Bérest, P., Ghoreychi, M., Hadj-Hassen, F., Tijani, M. (Eds.), Proc. $7^{\text {th }}$ Int. Conf. Mech. Behav. Salt (SaltMech7), Paris, France, pp. 433-442.

Lerche, S., 2012. Kriech- und Schädigungsprozesse im Salinargebirge bei mono- und multizyklischer Belastung. Ph.D. Dissertation, Technische Universität Clausthal, Clausthal-Zellerfeld, Germany, 319 pp. 
Leverett, M. C., 1941. Capillary behaviour in porous solids. Petroleum Transactions, AIME(192), 152-169.

Lowe, M.J.S., Knowles, N.C., 1989. Further benchmark exercises to compare geomechanical computer codes for salt (COSA II Proj.). Comm. Eur. Communities. Rep. EUR12135 EN, $418 \mathrm{pp}$.

Lux, K.-H., 1984. Gebirgsmechanischer Entwurf und Felderfahrung im Salzkavernenbau: Ein Beitrag zur Entwicklung von Prognosemodellen für den Hohlraumbau im duktilen Salzgebirge, $1^{\text {st }}$ edn. Ferdinand Enke Verlag, Stuttgart, Germany, 360 pp.

Millington, R.J., Quirk, J.P., 1961. Permeability of Porous Solids. Transactions of the Faraday Soc. 57, 1200-1207. doi: 10.1039/TF9615701200.

Minkley, W., Popp, T., 2012. Final Disposal in Rock Salt - Geomechanical Assessment of the Barrier Integrity. In: Proc. $44^{\text {th }}$ US Rock Mech./Geomech. Symp., Salt Lake City, UT, USA, pap. ARMA 10-492 (on CD-ROM).

Mönig, J., Beuth, T., Wolf, J., Lommerzheim, A., Mrugalla, S., 2013. Preliminary Safety Analysis of the Gorleben Site: Safety Concept and Application to Scenario Development Based on a Site-Specific Features, Events and Processes (FEP) Database-13304. In: Proc. WM2013 Conf., Phoenix, AZ, USA, 10 pp.

Munson, D.E., DeVries, K.L., Callahan, G.D., 1990. Comparison of calculations and in situ results for a large, heated test room at the Waste Isolation Pilot Plant (WIPP). In: Hustrulid, Johnson (Eds.), Proc. $31^{\text {st }}$ US Symp. Rock Mech., Golden, CO, USA, pp. 389396.

Munson, D.E., 1997. Constitutive model of creep in rock salt applied to underground room closure. Int. J. Rock Mech. Min. Sci. 34(2), 233-247. doi: 10.1016/S01489062(96)00047-2. 
Nutt, M., Voegele, M., Jové-Colón, C., Wang, Y., Howard, R., Blink, J., Liu, H.-H., Hardin, E., Jenni, K., 2011. Used Fuel Disposition Campaign Disposal Research and Development Roadmap. Prep. for US DOE Used Fuel Disposition Campaign. Rep. FCR\&D-USED2011-000065 Rev. 0, 121 pp.

Olivella, S., Gens, A., 2002. A constitutive model for crushed salt. Int. J. Numer. Anal. Methods Geomech. 26, 719-746. doi: 10.1002/nag.220.

Olivella, S., Castagna, S., Alonso, E.E., Lloret, A., 2011. Porosity Variations in Saline Media Induced by Temperature Gradients: Experimental Evidences and Modelling. Transp. Porous Med. 90, 763-777. doi: 10.1007/s11242-011-9814-x.

Peach, C.J., Spiers, C.J., 1996. Influence of crystal plastic deformation on dilatancy and permeability development in synthetic salt rock. Tectonophys. 256(1), 101-128. doi: 10.1016/0040-1951(95)00170-0.

Popp, T., Kern., H., 1998. Ultrasonic wave velocities, gas permeability and porosity in natural and granular rock salt. Phys. Chem. Earth 23(3), 373-378. doi: 10.1016/S00791946(98)00040-8

Popp, T., Minkley, W., 2010. Salt barrier integrity during gas pressure build-up in a radioactive waste repository - Implications from lab and field investigations. In: Proc. $44^{\text {th }}$ US Rock Mech./Geomech. Symp., Salt Lake City, UT, USA, pap. ARMA 10-493 (on CD-ROM).

Popp, T., Minkley, W., Salzer, K., Schulze, O., 2012. Gas transport properties of rock salt synoptic review. In: Bérest, P., Ghoreychi, M., Hadj-Hassen, F., Tijani, M. (Eds.), Proc. $7^{\text {th }}$ Int. Conf. Mech. Behav. Salt (SaltMech7), Paris, France, pp. 139-148.

Popp, T., Salzer, K., 2012. Microstructural Deformation Processes in Granular Salt during Mechanical Compaction. In Proc. $3^{\text {rd }}$ US/German Workshop on Salt Repository Research, Design and Operation Meet. Abstr., Albuquerque, NM, USA, p. 21. 
Pudewills, A., Müller-Hoeppe, N., Papp, R., 1995. Thermal and thermomechanical analyses for disposal in drifts of a repository in rock salt. Nucl. Technol. 112(1), 79-88.

Pruess, K., Oldenburg, C., Moridis, G., 2011. TOUGH2 User's Guide, Version 2. Lawrence Berkeley National Laboratory, Berkeley, CA, USA. Rep. LBNL-43134 (revised), 197 pp.

Rutqvist, J., Wu, Y.-S., Tsang, C.- F., Bodvarsson, G., 2002. A Modeling Approach for Analysis of Coupled Multiphase Fluid Flow, Heat Transfer, and Deformation in Fractured Porous Rock. Int. J. Rock Mech. Min. Sci. 39(4), 429-442. doi: 10.1016/S1365-1609(02)000229.

Rutqvist, J., Tsang, C.-F., 2003. TOUGH-FLAC: a numerical simulator for analysis of coupled thermal-hydrologic-mechanical processes in fractured and porous geological media under multi-phase flow conditions. In: Proc. TOUGH Symp. 2003, Berkeley, CA, USA, $12 \mathrm{pp}$.

Rutqvist, J., 2011. Status of the TOUGH-FLAC simulator and recent applications related to coupled fluid flow and crustal deformations. Comput. Geosci. 37(6), 739-750. doi: 10.1016/j.cageo.2010.08.006.

Rutqvist, J., Blanco Martín, L., Kim, J., Birkholzer, J.T., 2013. Modeling coupled THMC processes and Brine Migration in Salt at High Temperatures. Lawrence Berkeley National Laboratory (Prep. for US DOE Used Fuel Disposition Campaign), Berkeley, CA, USA. Rep. FCRD-UFD-2013-000262, 46 pp.

Schulze, O., Popp, T., Kern, H., 2001. Development of damage and permeability in deforming rock salt. Eng. Geol. 61, 163-180. doi: 10.1016/S0013-7952(01)00051-5.

Settari, A., Mourits, F., 1998. A coupled reservoir and geomechanical simulation system. SPE J. 3(3), 219-226. doi: 10.2118/50939-PA.

Settari, A., Walters, D.A., 2001. Advances in coupled geomechanical and reservoir modeling with applications to reservoir compaction. SPE J. 6(3), 334-342. doi: 10.2118/74142-PA. 
Sjaardema, G.D., Krieg, R.D., 1987. A Constitutive Model for the Consolidation of WIPP Crushed Salt and Its Use in Analyses of Backfilled Shaft and Drift Configurations. Sandia Natl. Labs., Albuquerque, NM, USA. Rep. SAND-87-1977, 72 pp.

Stone, C.M., Holland, J.F., Bean, J.E., Argüello, J.G., 2010. Coupled Thermal-Mechanical Analyses of a Generic Salt Repository for High-Level Waste. In: Proc. $44^{\text {th }}$ US Rock Mech./Geomech. Symp., Salt Lake City, UT, USA, pap. ARMA 10-180 (on CD-ROM).

Stormont, J.C., Daemen, J.J.K., 1992. Laboratory study of gas permeability changes in rock salt during deformation. Int. J. Rock Mech. Min. Sci. 29(4), 325-342. doi: 10.1016/01489062(92)90510-7.

Thomas, L.K., Chin, L.Y., Pierson, R.G., Sylte, J.E., 2003. Coupled geomechanics and reservoir simulation. SPE J. 8(4), 350-358. doi: 10.2118/87339-PA.

Tsang, C.-F., Stephansson, O., Jing, L., Kautsky, F., 2009. DECOVALEX Project: from 1992 to 2007. Environ. Geol. 57, 1221-1237. doi: 10.1007/s00254-008-1625-1.

van Genuchten, M.T., 1980. A closed-form equation for predicting the hydraulic conductivity of unsaturated soils. Soil Sci. Soc. Am. J. 44(5), 892-898. doi: 10.2136/sssaj1980.03615995004400050002x.

Vargaftik, N.B., 1975. Tables on the Thermophysical Properties of Liquids and Gases, $2^{\text {nd }}$ edn. Hemisphere Publishing, New York, USA, 758 pp. doi: 10.1002/aic.690210636.

Vijalapura, P.K., Strain, J., Govindjee, S., 2005. Fractional step methods for index-1 differentialalgebraic equations. J.Comput. Phys. 203, 305-320. doi: 10.1016/j.jcp.2004.08.015.

Walker, W.R., Sabey, J.D., Hampton, D.R., 1981. Studies of Heat Transfer and Water Migration in Soils. Department Agric. Chem. Eng., Colorado State University, Fort Collins, CO, USA. Final Rep., 140 pp.

Wieczorek, K., Czaikowski, O., Zhang, C.-L., Stührenberg, D., 2012. Recent Experimental and Modeling Results on Crushed Salt Consolidation. In: Proc. $3^{\text {rd }}$ US/German Workshop on 
Salt Repository Research, Design and Operation Meet. Abstr., Albuquerque, NM, USA, p. 22.

Wolters, R., Lux, K.-H., Düsterloh, U., 2010. Evaluation of Rock Salt Barriers with Respect to Tightness: Influence of Thermomechanical Damage, Fluid Infiltration and Sealing/Healing. In: Proc. $44^{\text {th }}$ US Rock Mech./Geomech. Symp., Salt Lake City, UT, USA, pap. ARMA 10-215 (on CD-ROM).

Wolters, R., Lux, K.-H., Düsterloh, U., 2012. Evaluation of Rock Salt Barriers with Respect to Tightness: Influence of Thermomechanical Damage, Fluid Infiltration and Sealing/Healing. In: Bérest, P., Ghoreychi, M., Hadj-Hassen, F., Tijani, M. (Eds.), Proc. $7^{\text {th }}$ Int. Conf. Mech. Behav. Salt (SaltMech7), Paris, France, pp. 417-426. 
Table 1. Mechanical and flow properties of the crushed salt, natural salt and confining layers.

\begin{tabular}{|c|c|c|c|}
\hline Property [unit] & Crushed salt & Rock salt & Confining rock \\
\hline Grain density, $\rho\left[\mathrm{kg} \cdot \mathrm{m}^{-3}\right]$ & 2200 & 2200 & 2600 \\
\hline$K[\mathrm{MPa}]$ & $150^{\mathrm{a}}$ & $16,650^{b}$ & 37,900 \\
\hline G [MPa] & $70^{a}$ & $7690^{b}$ & 19,500 \\
\hline$\alpha_{T}\left[\mathrm{~K}^{-1}\right]$ & $4 \cdot 10^{-5}$ & $4 \cdot 10^{-5}$ & $10^{-5}$ \\
\hline$\alpha[-]$ & $1^{a}$ & $0.003^{b}$ & 1 \\
\hline Relative permeability functions & Corey & Corey & $\begin{array}{c}\text { Van Genuchten } \\
\text { (liquid), Corey } \\
\text { (gas) }\end{array}$ \\
\hline Residual liquid saturation, $S_{I r}[-]$ & 0.1 & 0.1 & 0.02 \\
\hline Residual gas saturation, $S_{g r}[-]$ & 0 & 0 & 0.01 \\
\hline Van Genuchten's $\lambda[-]$ & 0.6 & 0.6 & 0.6 \\
\hline Van Genuchten's $P_{0}[\mathrm{MPa}]$ & $0.0004^{c}$ & $5.7^{\mathrm{c}}$ & 3.6 \\
\hline Van Genuchten's $S_{l r}[-]$ & 0.01 & 0.01 & 0.01 \\
\hline
\end{tabular}


Table 2. Initial flow parameters of the crushed salt, natural salt and confining layers.

\begin{tabular}{cccc}
\hline Parameter [unit] & Crushed salt & Rock salt & Confining rock \\
\hline$S_{\text {I }}[-]$ & 0.015 & 1 & 1 \\
$\phi[-]$ & $30 \%$ & $0.2 \%$ & $12 \%$ \\
$k\left[\mathrm{~m}^{2}\right]$ & $3 \cdot 10^{-13}$ & $10^{-22}$ & $10^{-17 a}$ \\
$C\left[\mathrm{~J} \cdot \mathrm{kg}^{-1} \mathrm{~K}^{-1}\right]$ & 860 & 860 & $900^{\mathrm{a}}$ \\
$\lambda\left[\mathrm{W} \cdot \mathrm{m}^{-1} \mathrm{~K}^{-1}\right]$ & 0.9 & 4 & $1.8^{\mathrm{a}}$ \\
\hline \multicolumn{4}{c}{$:$ constant values }
\end{tabular}


$t^{n-1}$

$$
t^{n} \quad \Delta t^{n+1}=t^{n+1}-t^{n}
$$$$
t^{n+1}
$$

Time

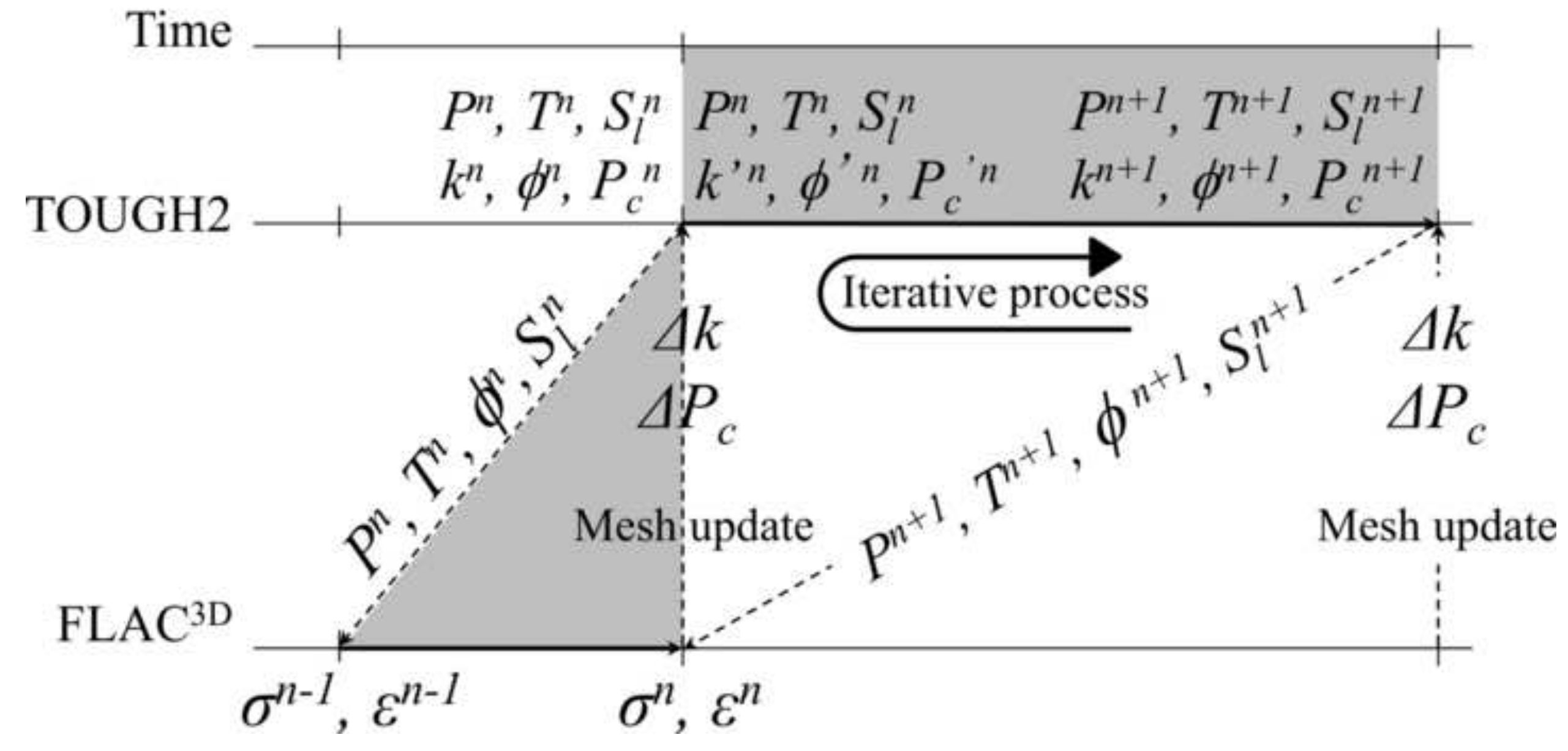


Figure 2a (color for online version)

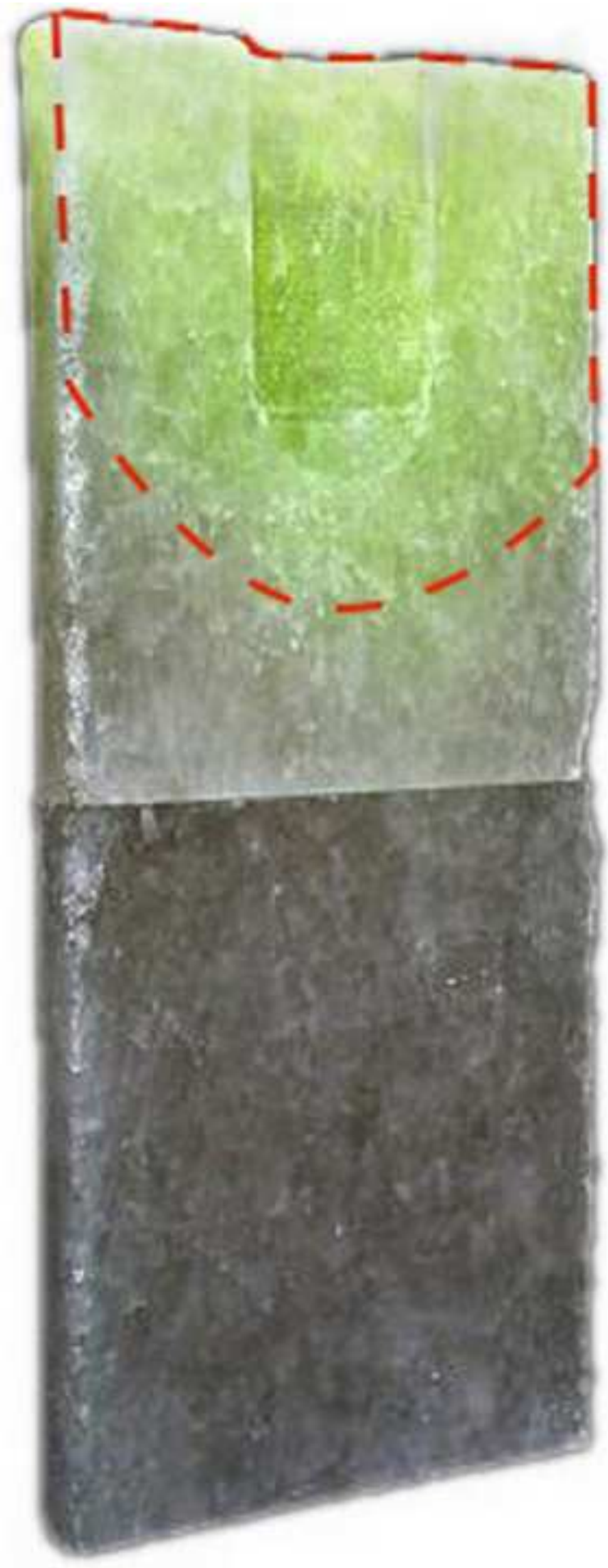


Figure $2 b$ (color for online version)

\section{$\triangle P_{\mathrm{Fl}}[\mathrm{MPa}]$}

$2.1024 \mathrm{E}+00$

$2.0000 \mathrm{E}+00$

$1.8000 \mathrm{E}+00$

$1.6000 \mathrm{E}+00$

$1.4000 \mathrm{E}+00$

$1.2000 \mathrm{E}+00$

$1.0000 \mathrm{E}+00$

$8.0000 \mathrm{E}-01$

6.0000E-01

4.0000E-01

2.0000E-01

$0.0000 \mathrm{E}+00$

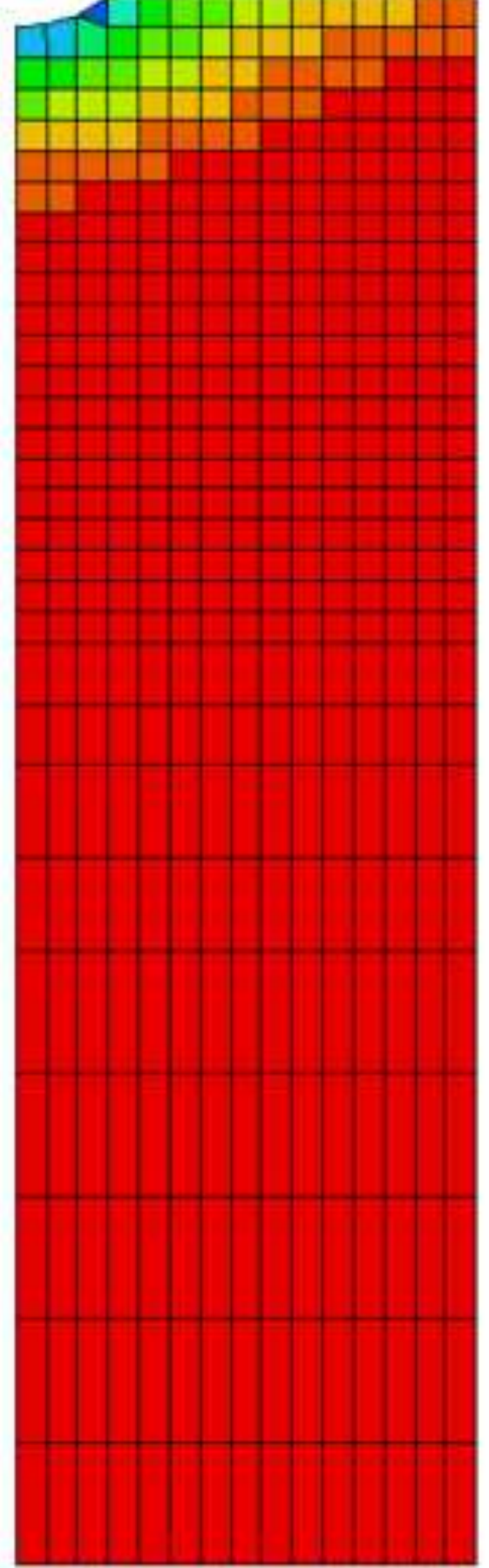


Figure 2a (black\&white for printed version)
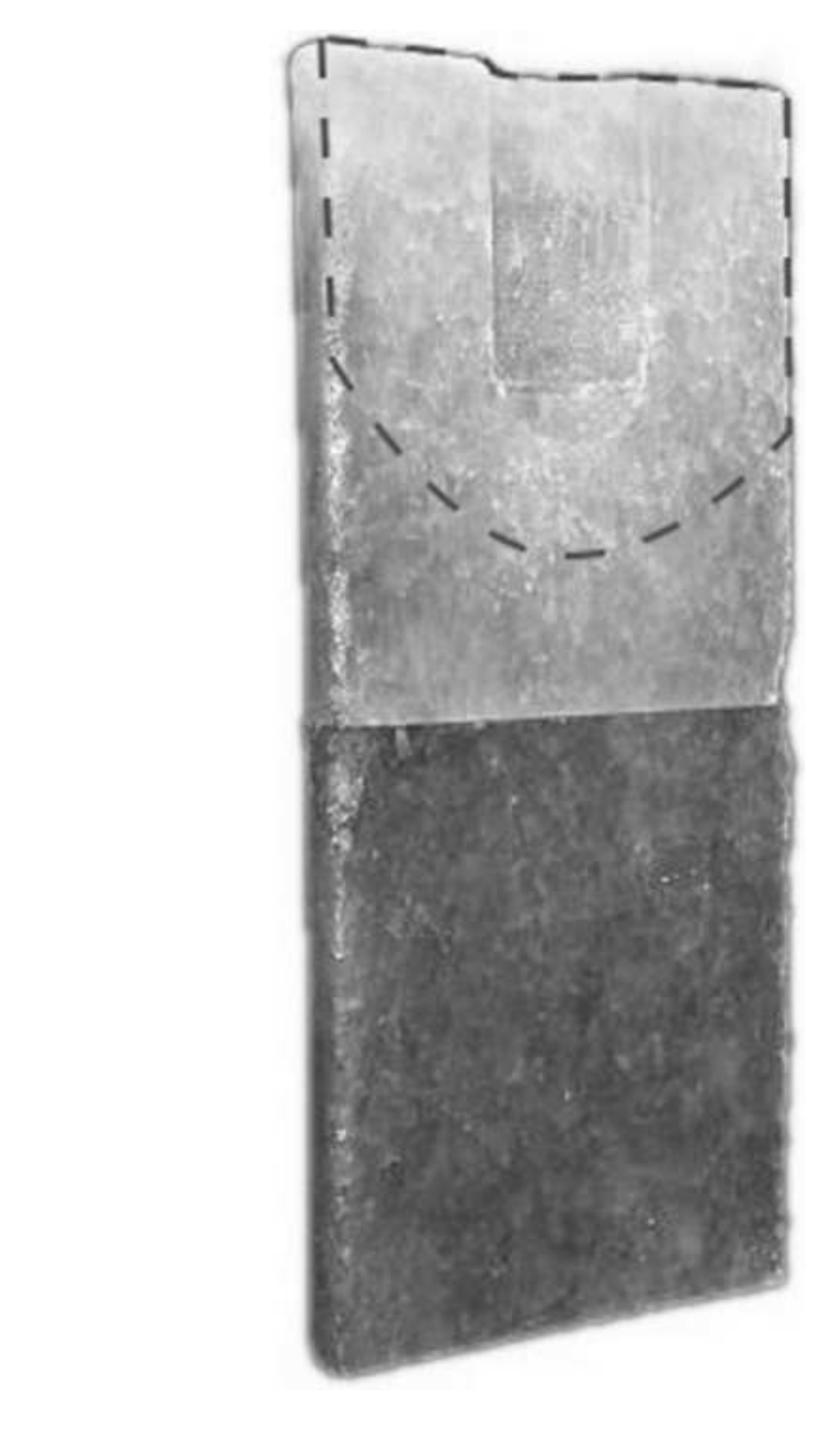

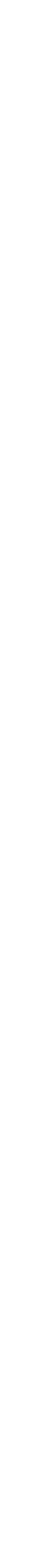


Figure $2 b$ (black\&white for printed version)

\section{$\triangle P_{F I}[\mathrm{MPa}]$}

$2.1024 \mathrm{E}+00$

$2.0000 \mathrm{E}+00$

$1.8000 \mathrm{E}+00$

$1.6000 \mathrm{E}+00$

$1.4000 \mathrm{E}+00$

$1.2000 \mathrm{E}+00$

$1.0000 \mathrm{E}+00$

$8.0000 \mathrm{E}-01$

$6.0000 \mathrm{E}-01$

4.0000E-01

2.0000E-01

$0.0000 E+00$

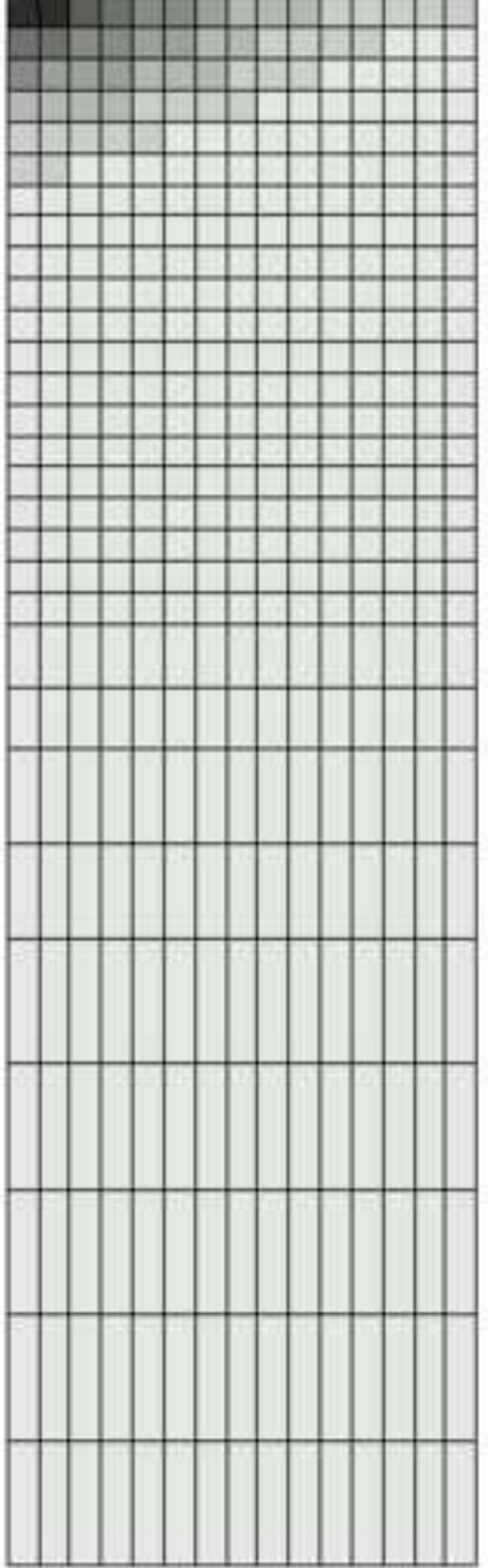




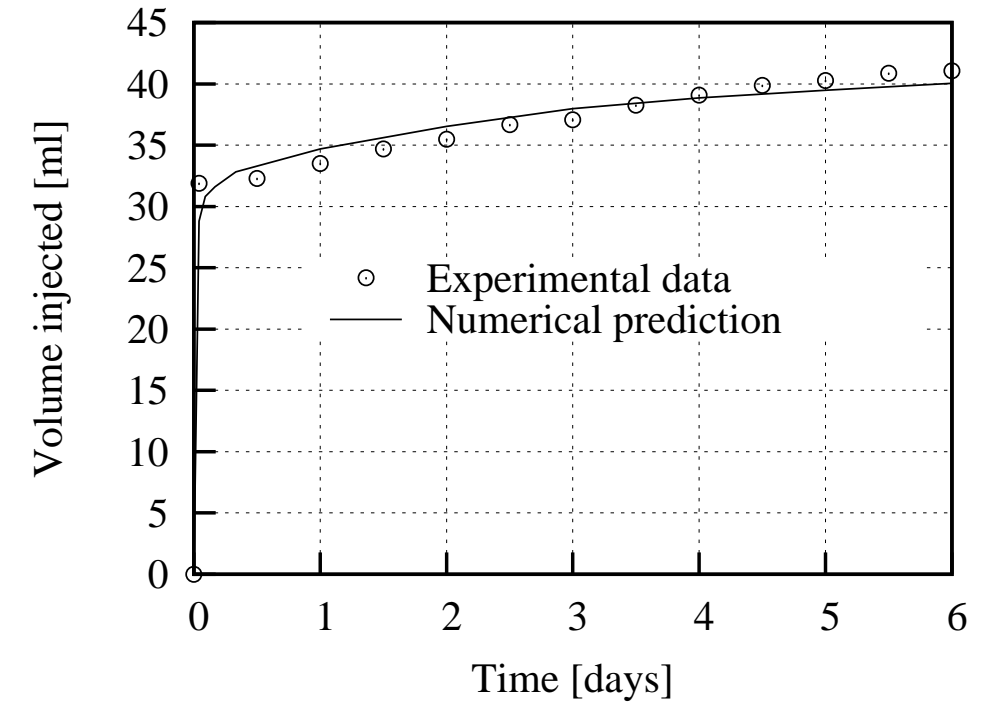




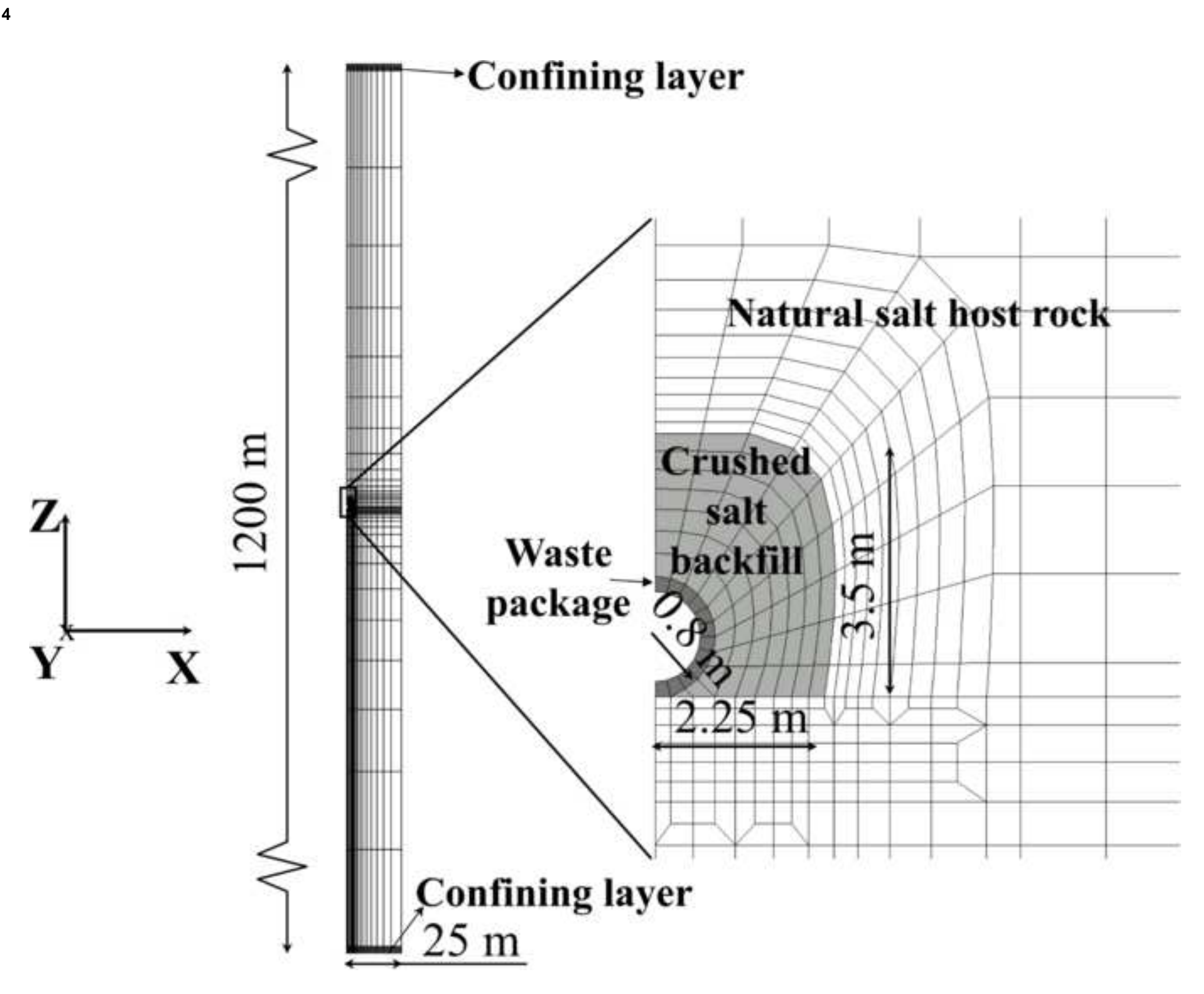

.
. 柆

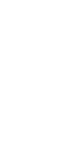




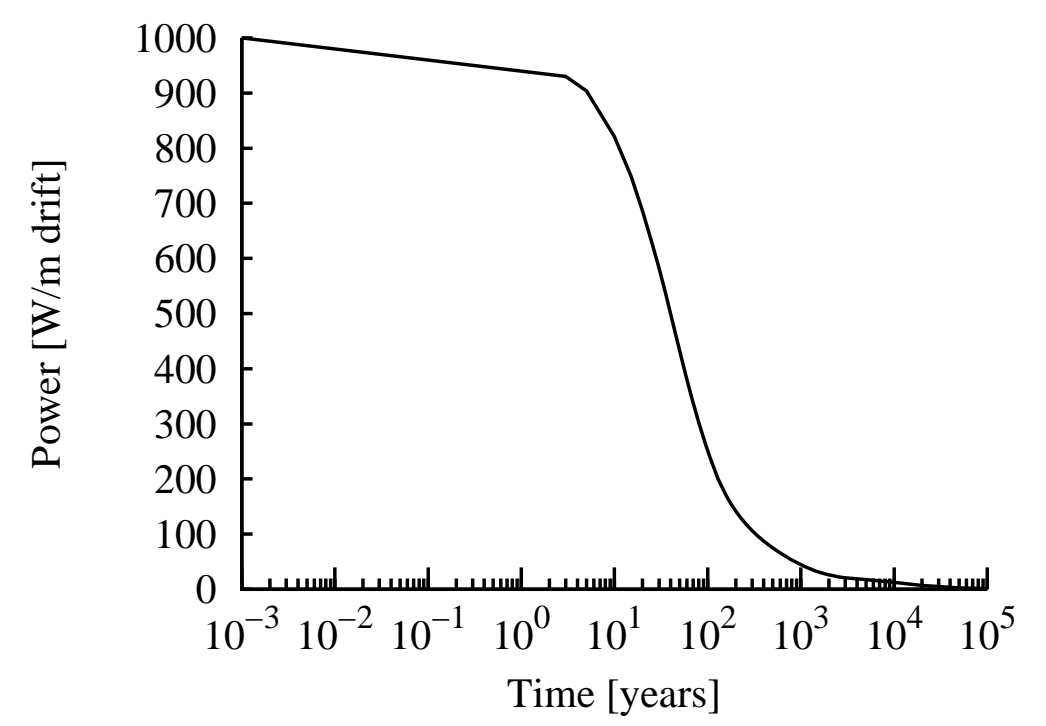


Figure 6 (color for online version)

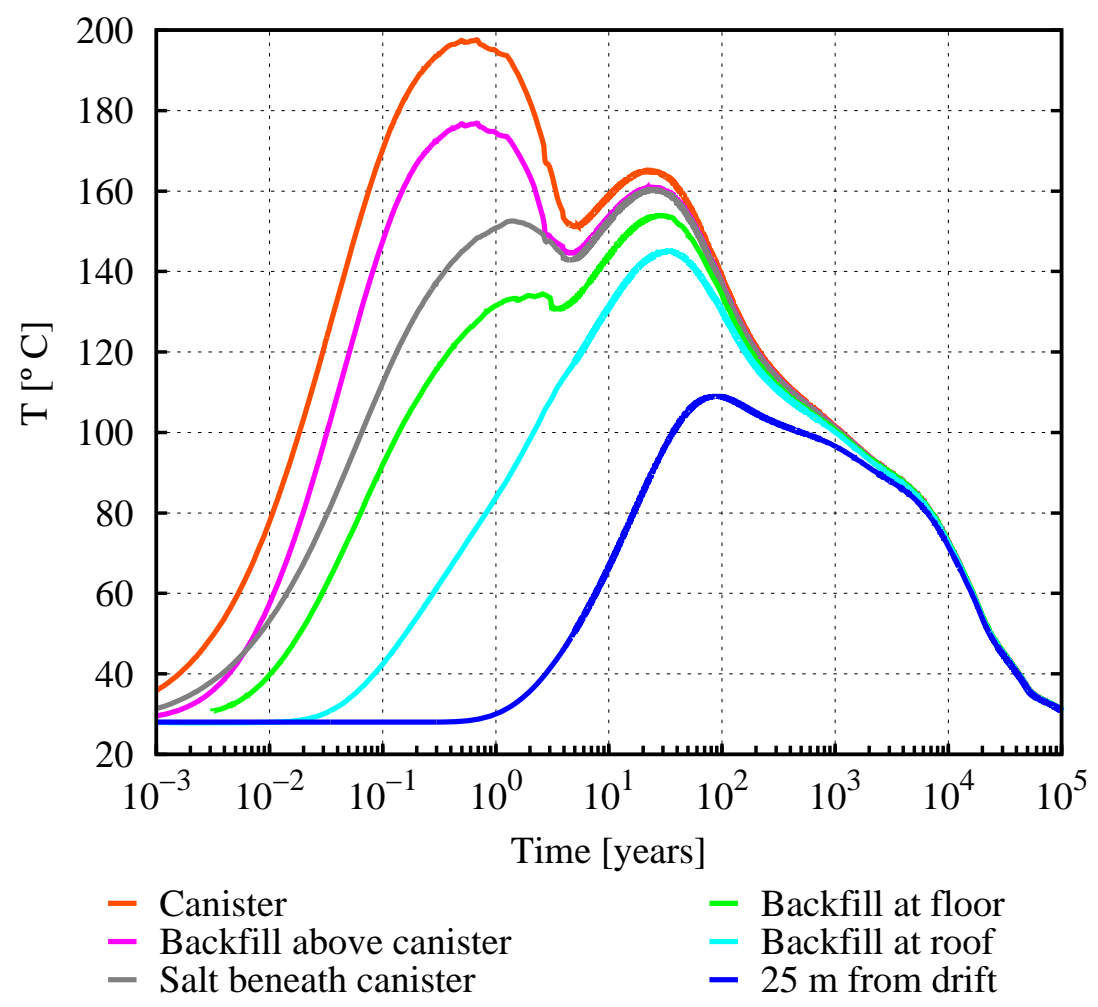


Figure 6 (black\&white for printed version)

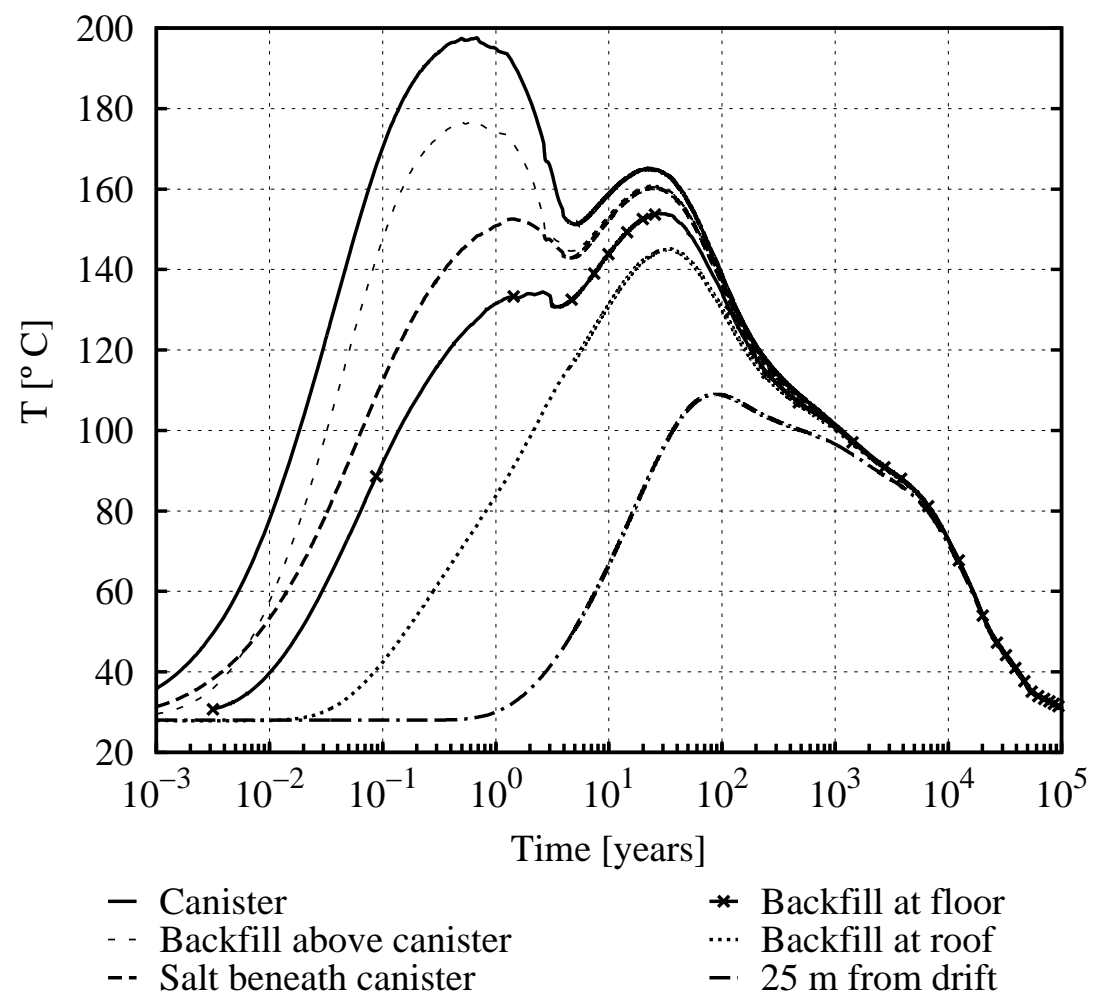


Figure 7 (color for online version)

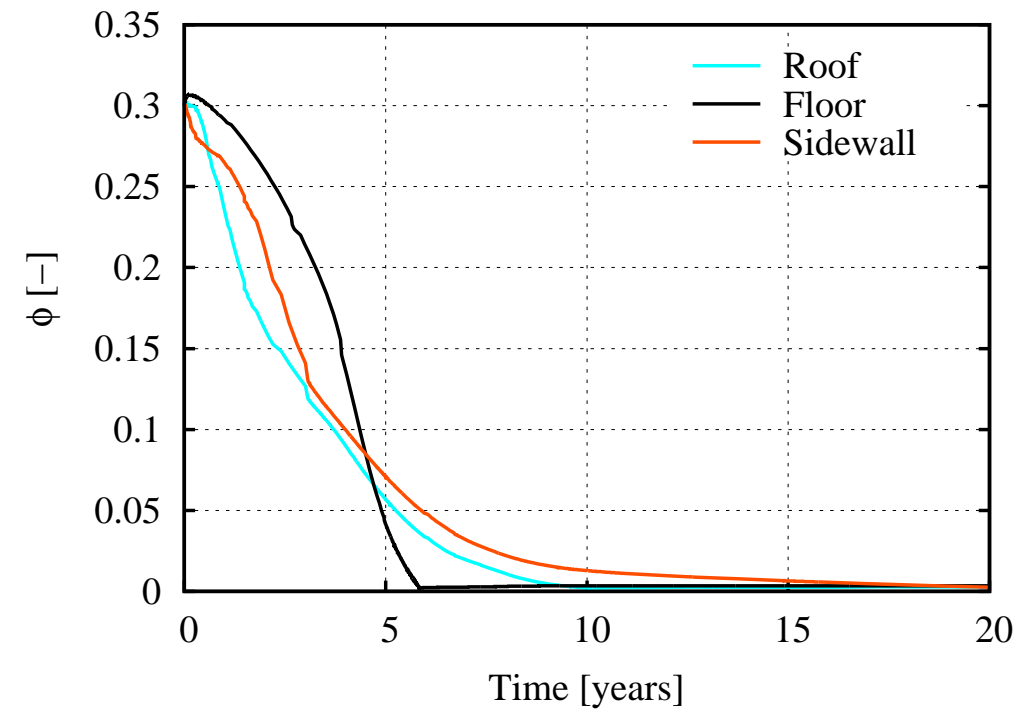


Figure 7 (black\&white for printed version)

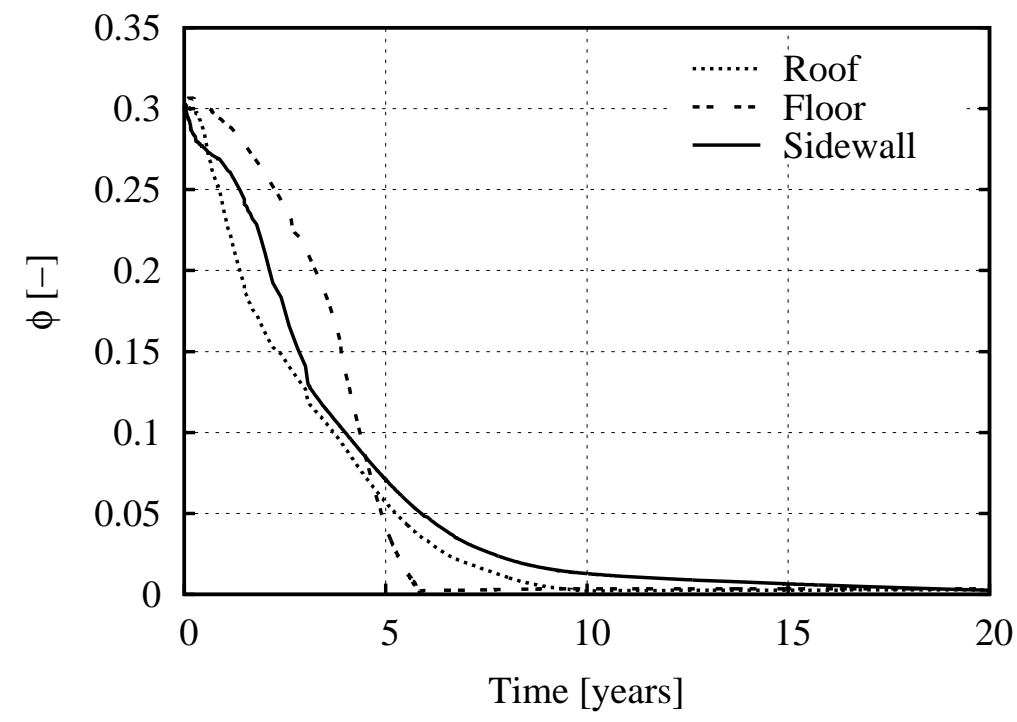


After excavation $(t=0 \mathrm{~s})$

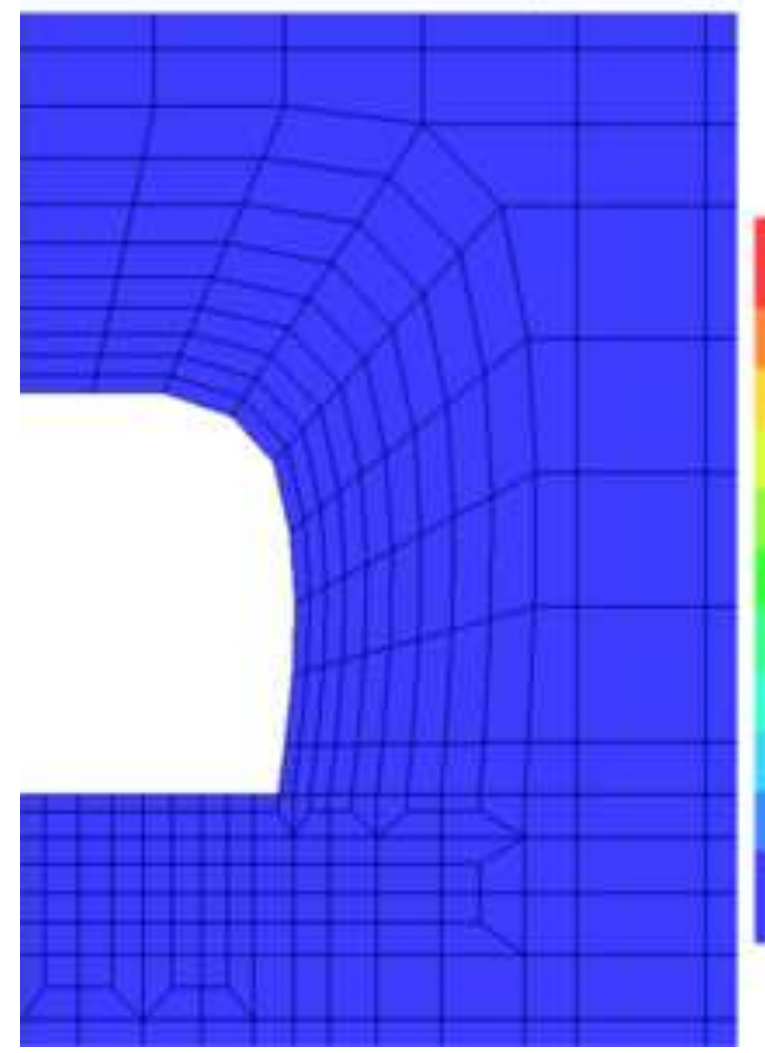

$$
t=4 \text { years }
$$

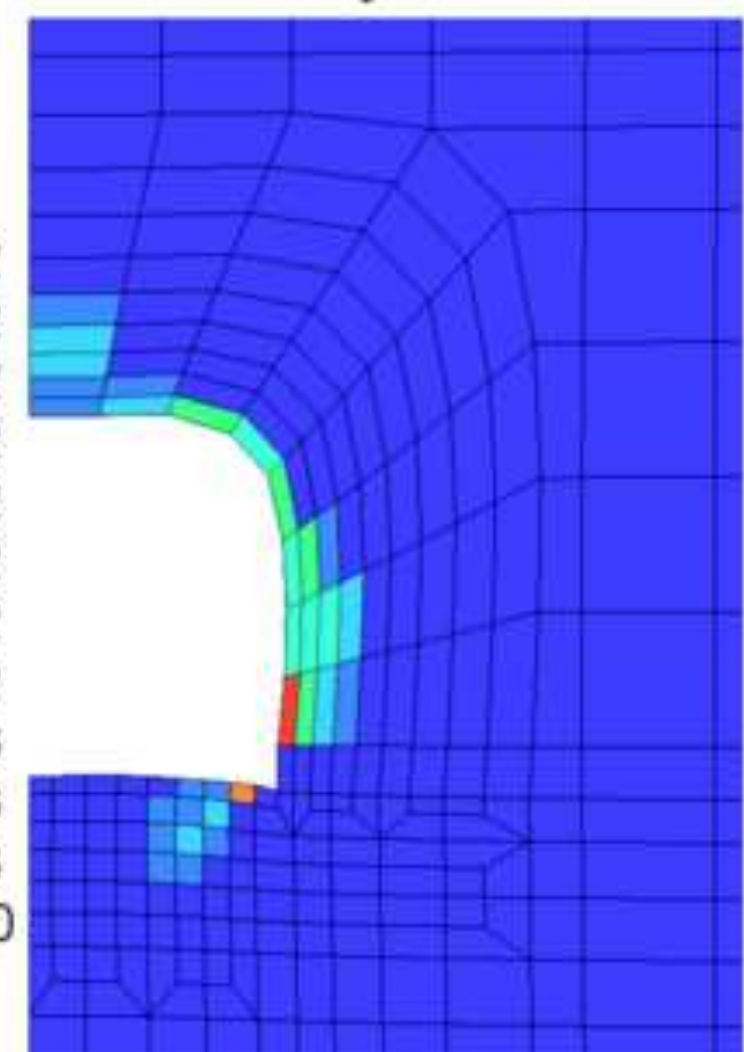

$t=7$ years

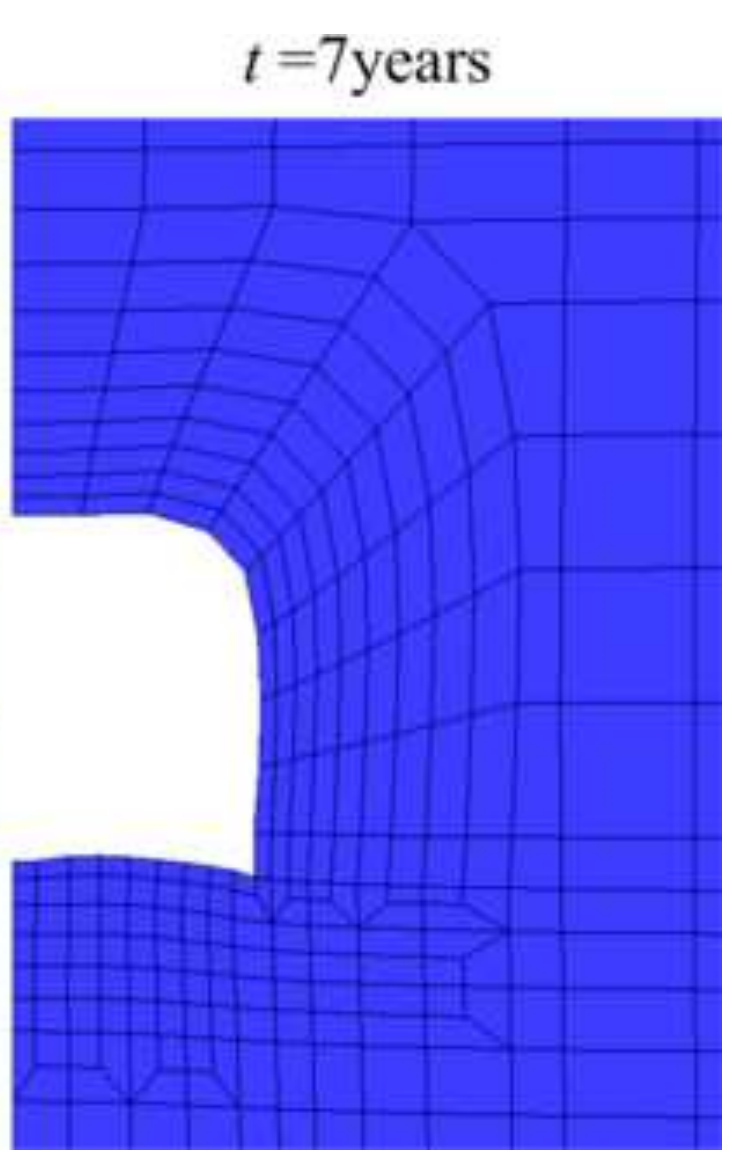

2.60E-02

$2.50 \mathrm{E}-02$

$2.25 \mathrm{E}-02$

$2.00 \mathrm{E}-02$

1.75E-02

1.50E-02

1.25E-02

1.00E-02

$7.50 \mathrm{E}-03$

$5.00 \mathrm{E}-03$

$2.50 \mathrm{E}-03$

$0.00 \mathrm{E}+00$ 
After excavation $(t=0 \mathrm{~s})$

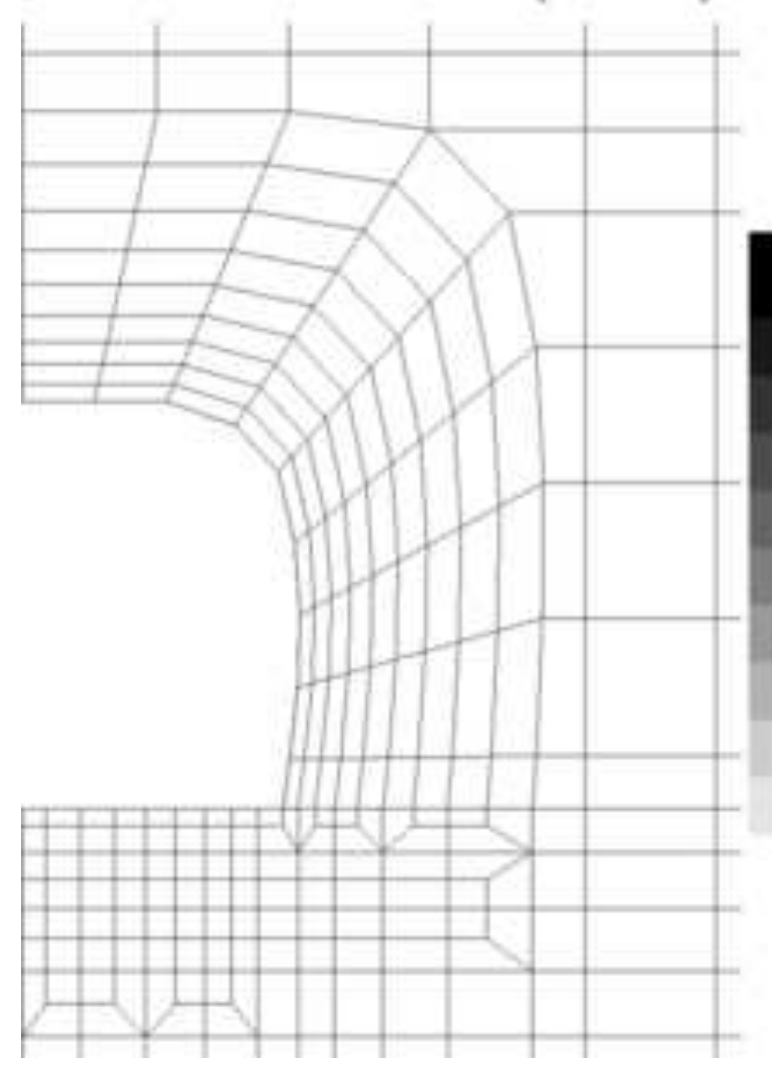

2.60 E-02

2.50 E-02

2.25E-02

2.00E-02

1.75E-02

1.50E-02

1.25E-02

$1.00 \mathrm{E}-02$

7.50E-03

$5.00 \mathrm{E}-03$

2.50E-03 $0.00 E+00$
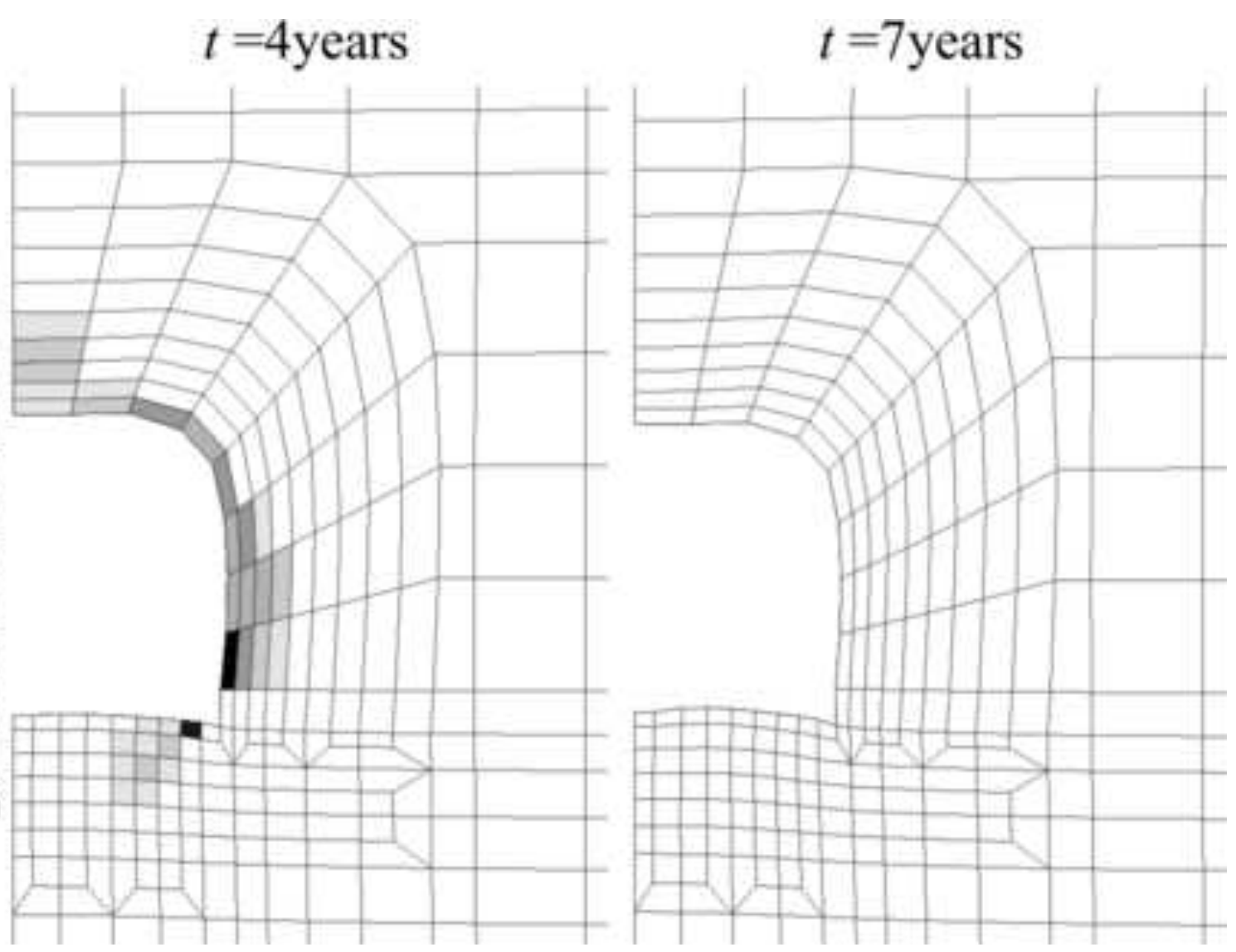
Figure 9a (color for online version)

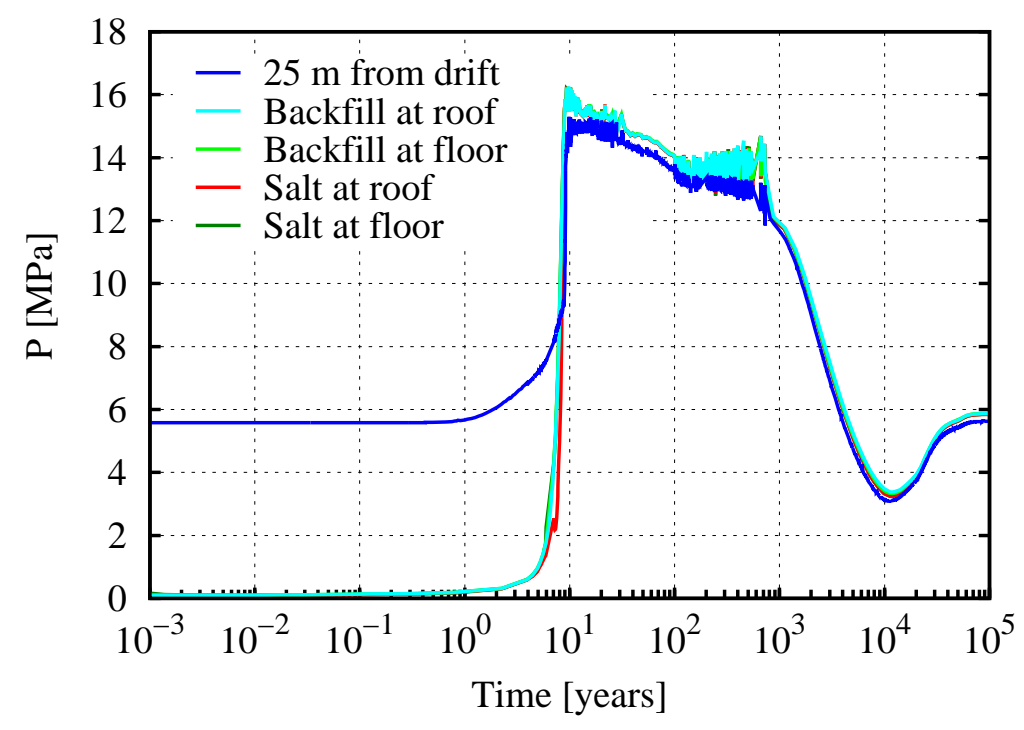


Figure 9b (color for online version)

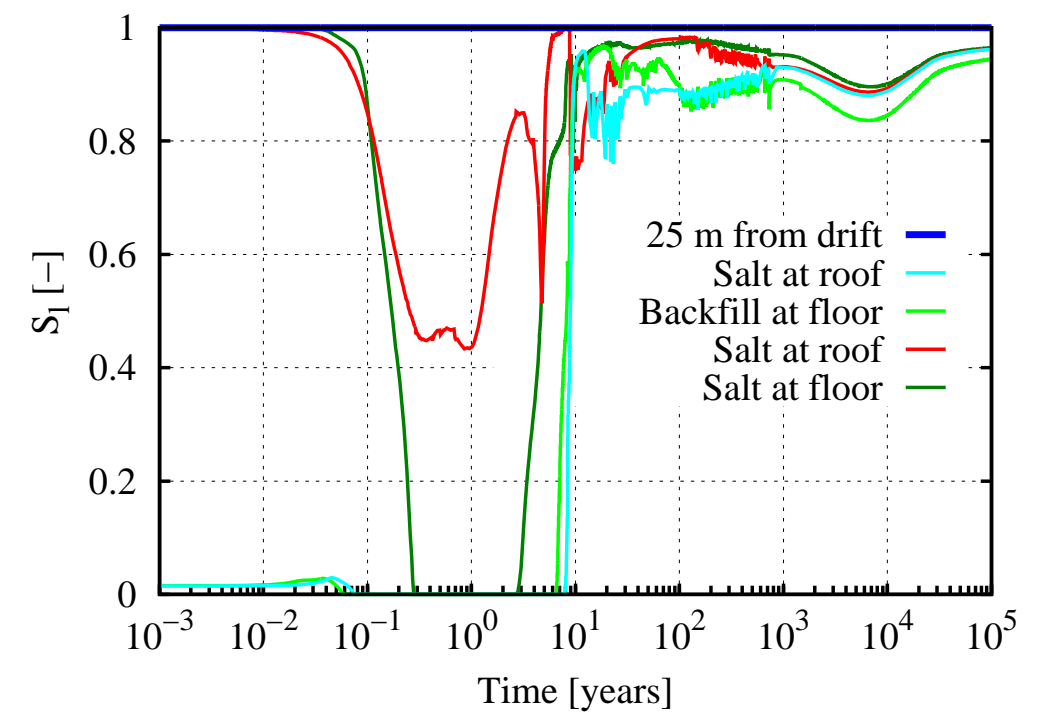


Figure 9a (black\&white for printed version)

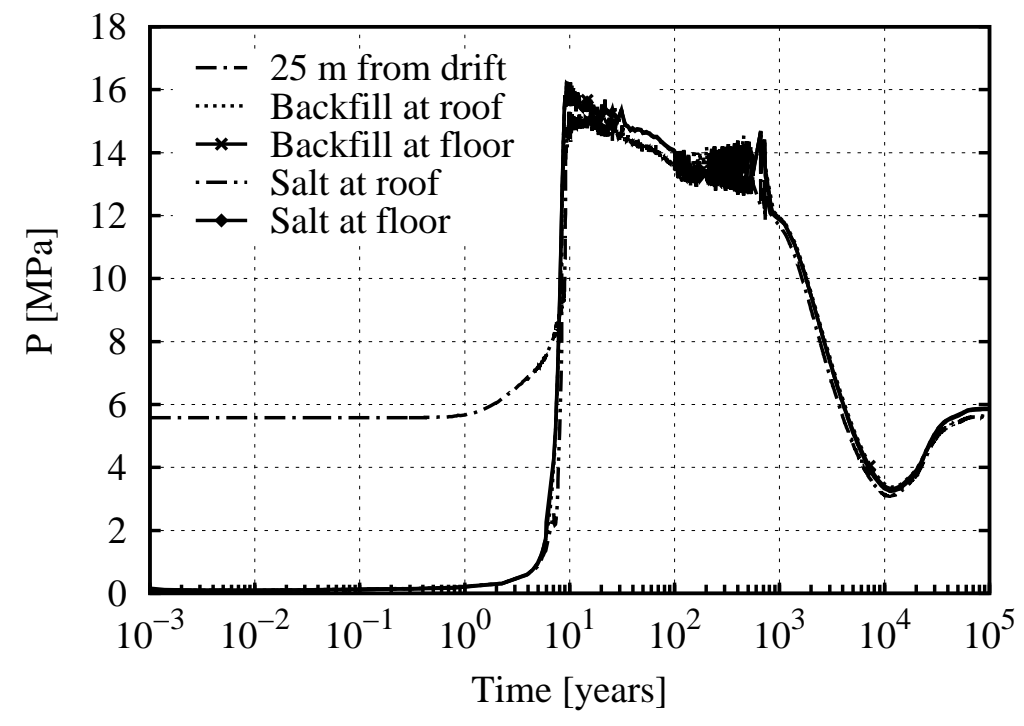


Figure $9 b$ (black\&white for printed version)

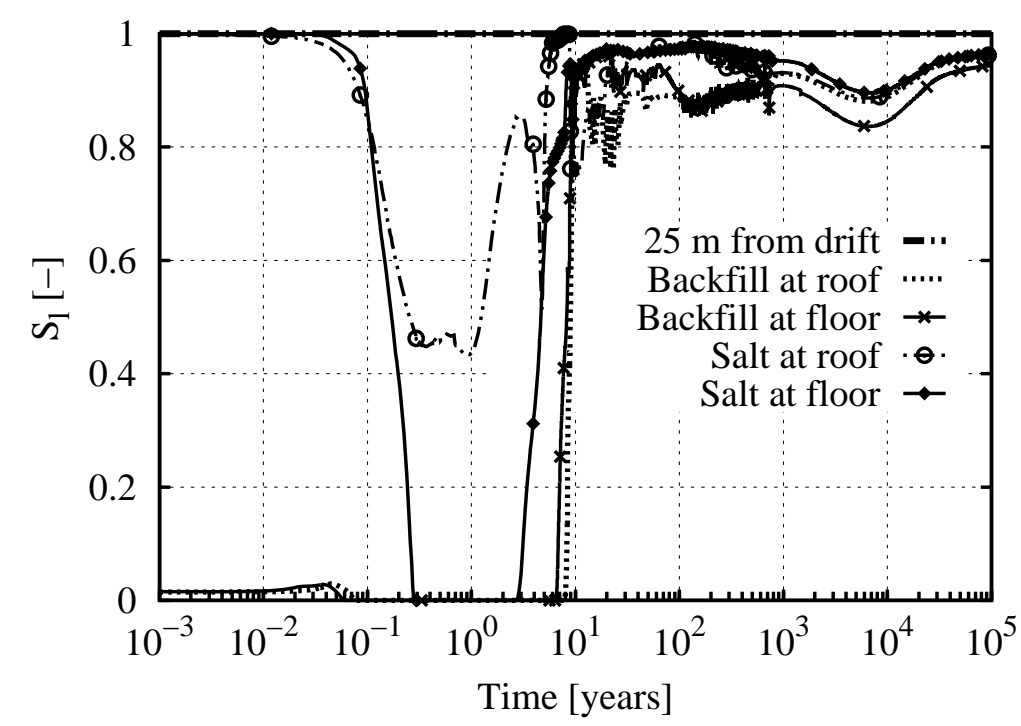


Figure 10 (color for online version)

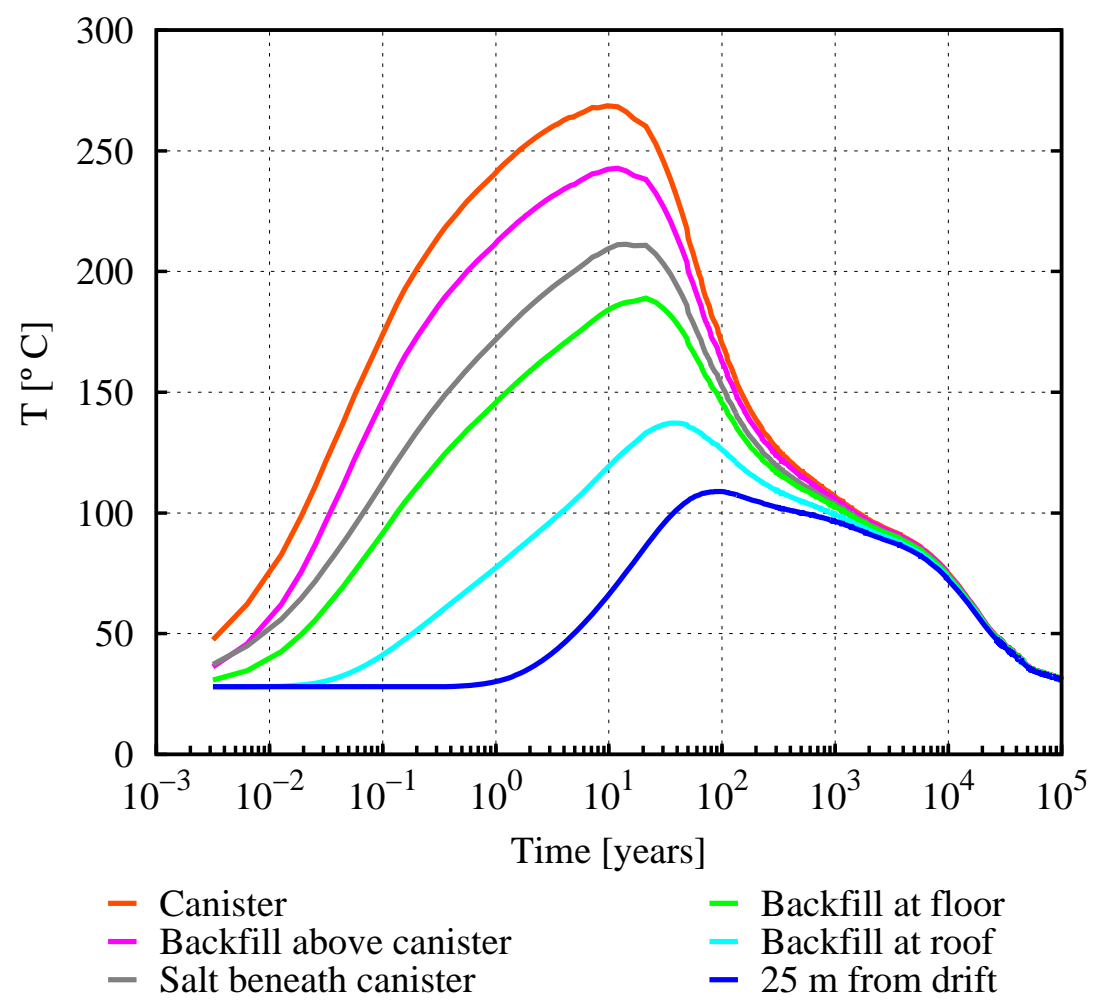


Figure 10 (black\&white for printed version)

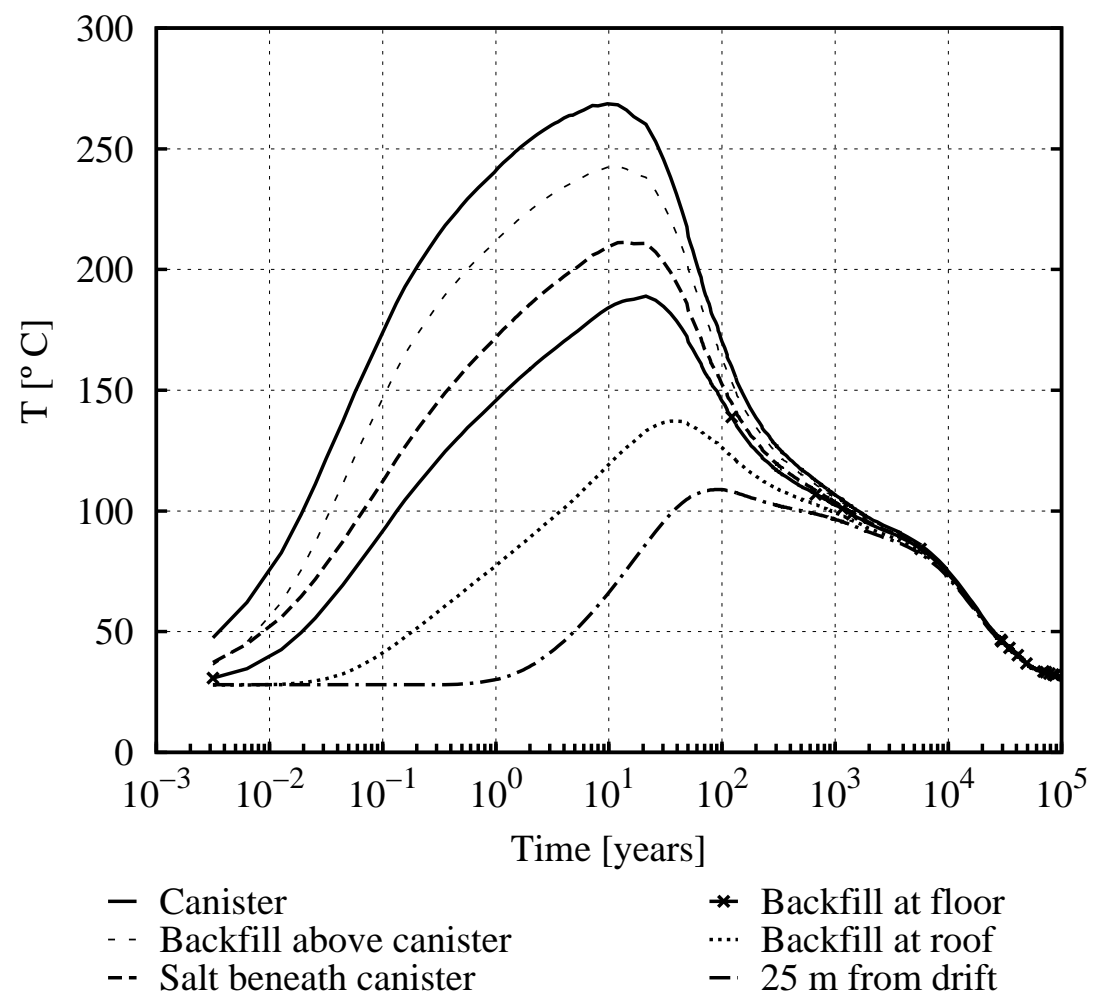


Figure 11a (color for online version)

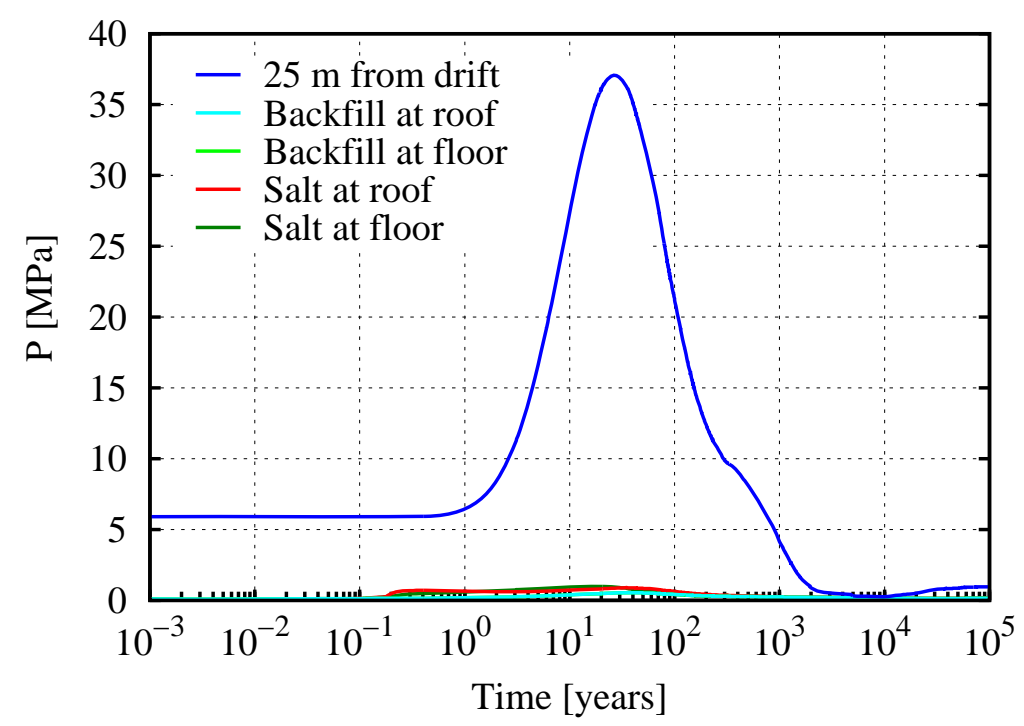


Figure 11b (color for online version)

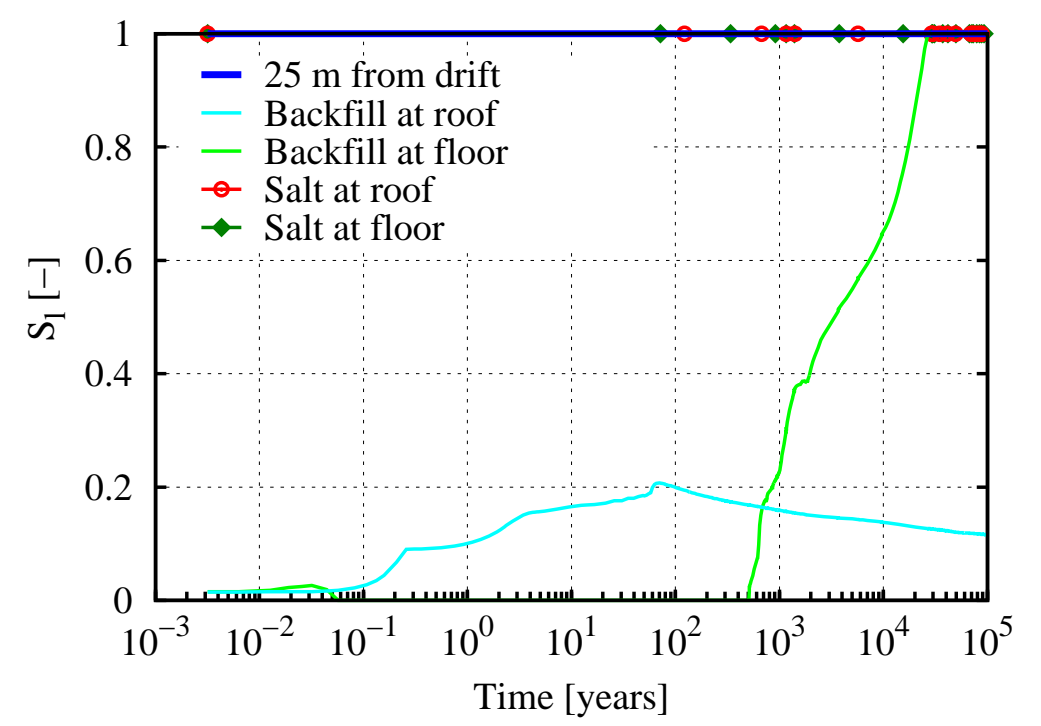


Figure 11a (black\&whie for printed version)

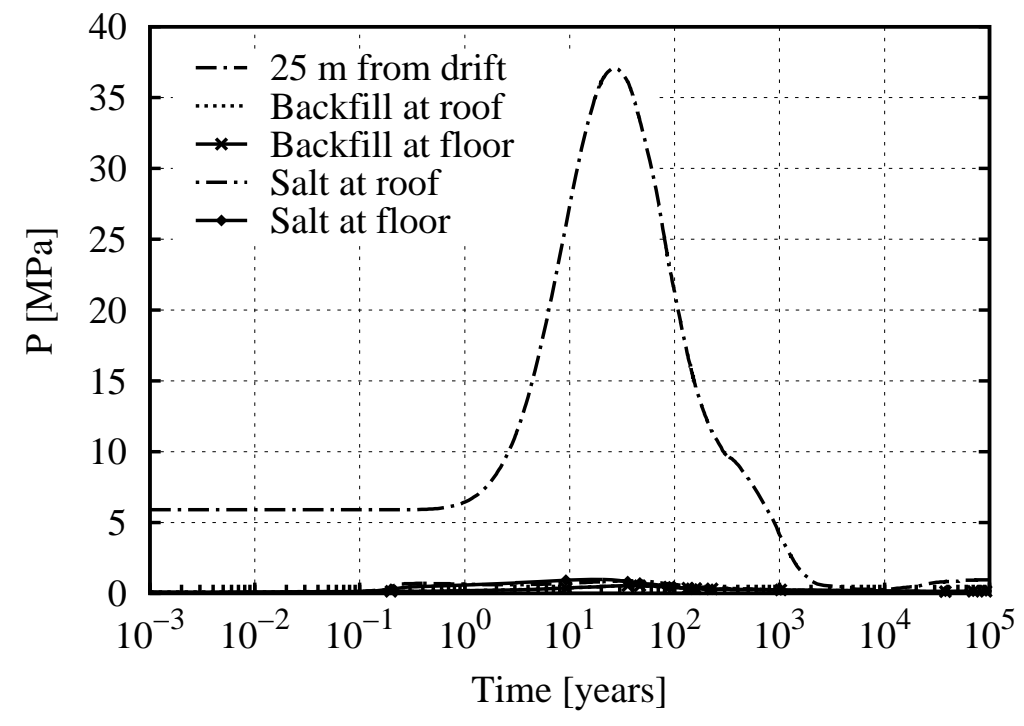


Figure $11 b$ (black\&white for printed version)

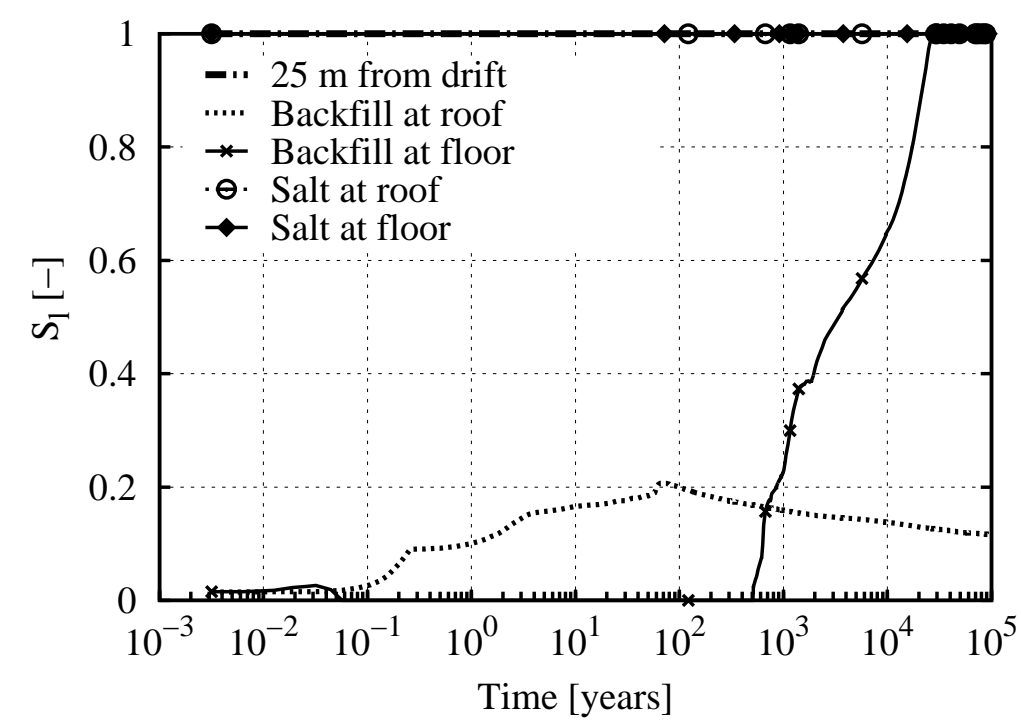


Figure $12 \mathrm{a}$ (color for online version)

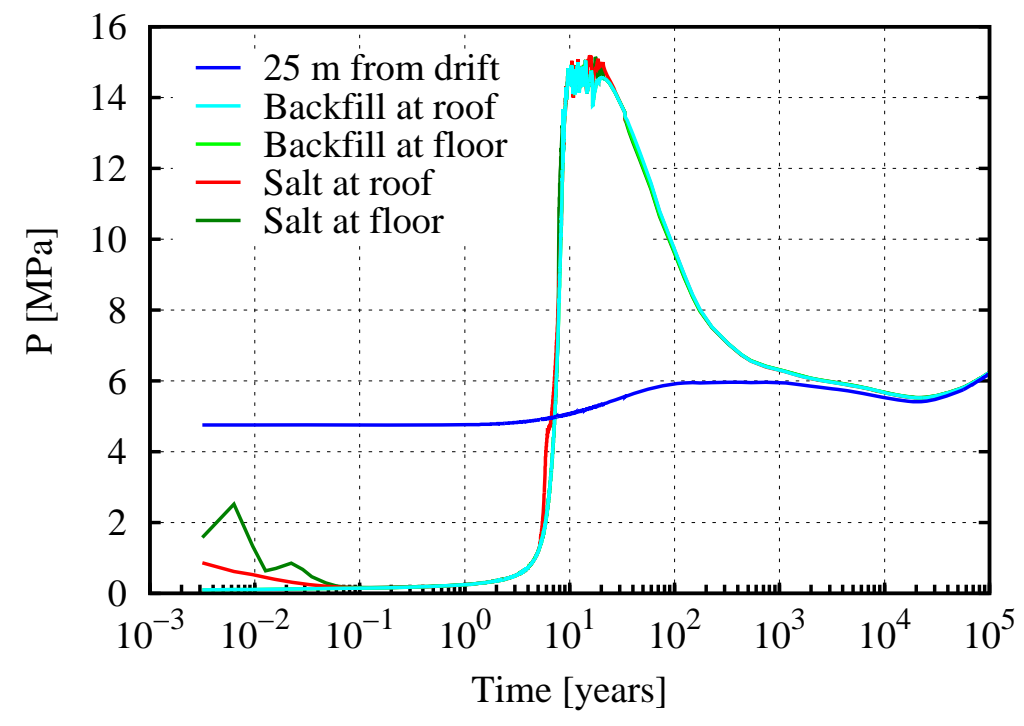


Figure $12 b$ (color for online version)

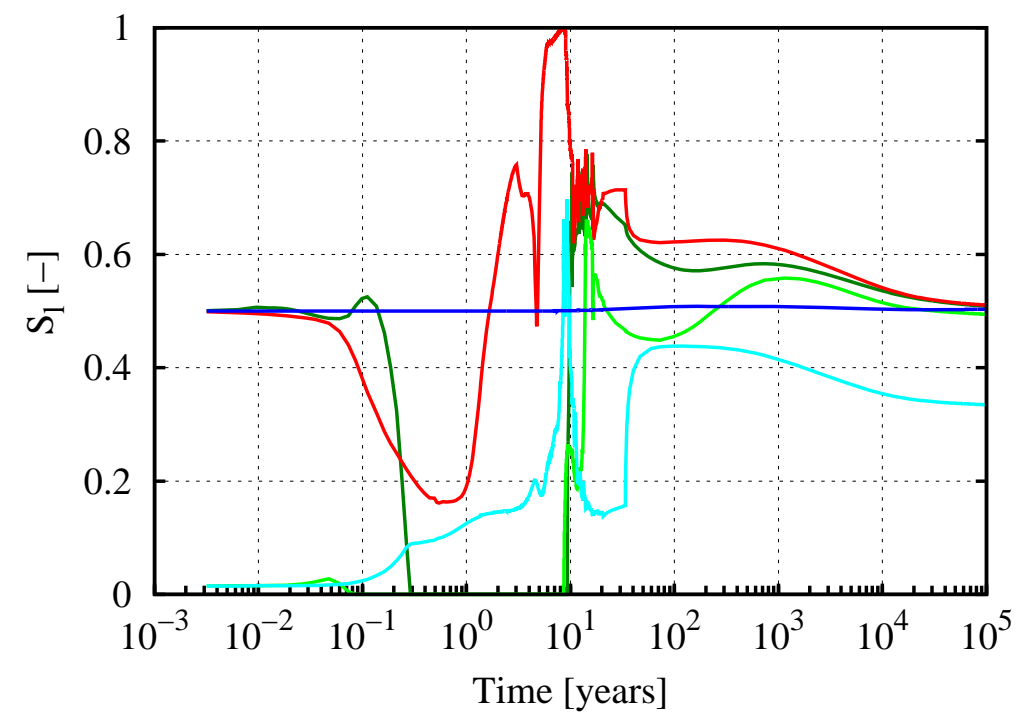

- Backfill at floor

- Salt at roof

- $25 \mathrm{~m}$ from drift

- Salt at floor

- Backfill at roof 
Figure 12a (black\&white for printed version)

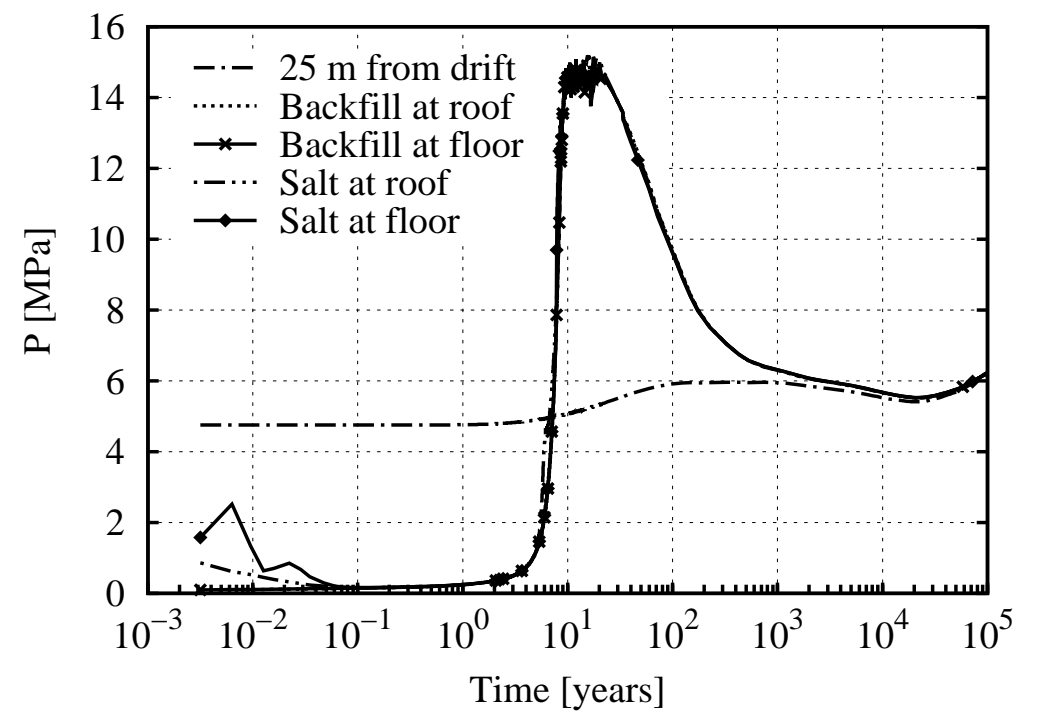




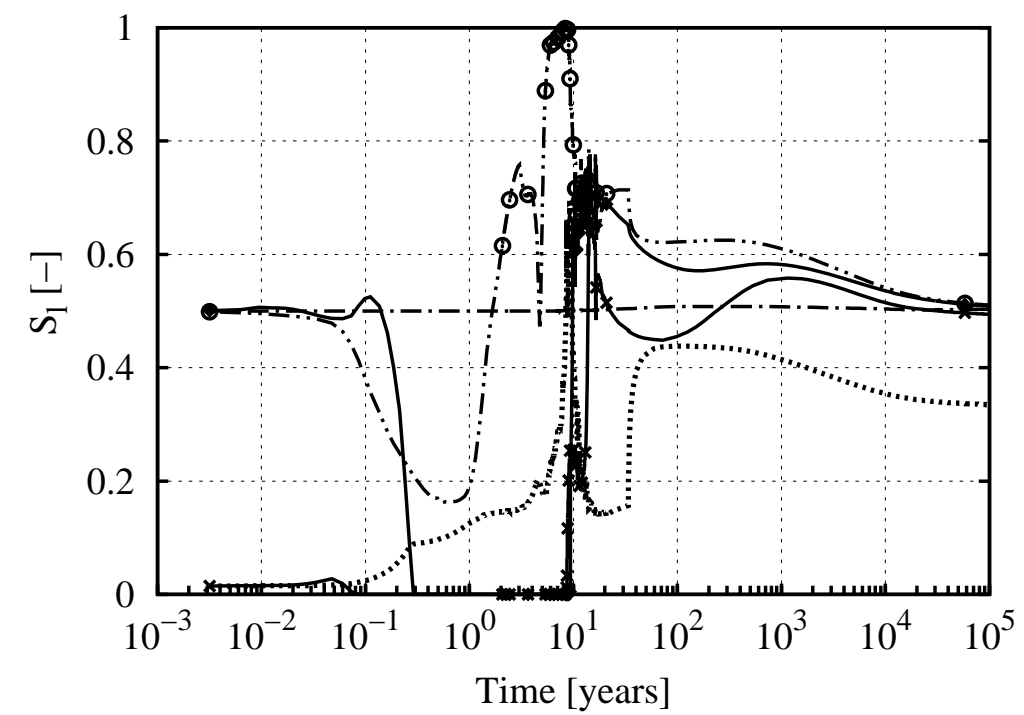

* Backfill at floor

- $\bullet$.. Salt at roof

-.- $25 \mathrm{~m}$ from drift

$\rightarrow$ Salt at floor ....... Backfill at roof

\section{Figure 12b (black\&white for printed version)}

Time [years] 
Figure $13 a$ (color for online version)

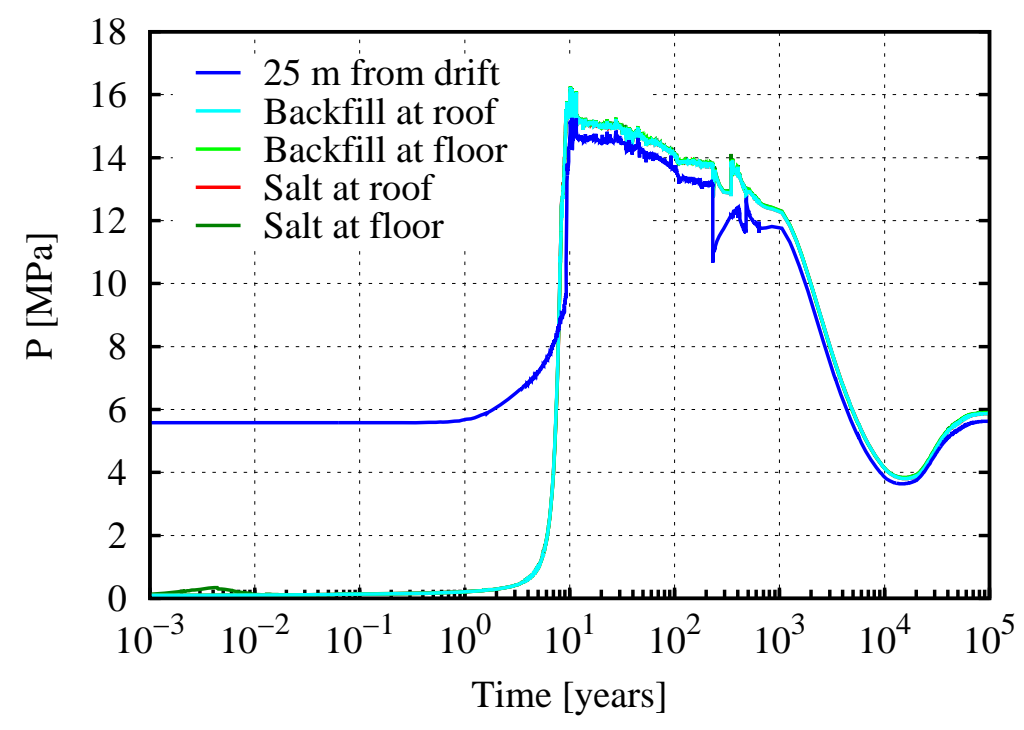


Figure $13 \mathrm{~b}$ (color for online version)

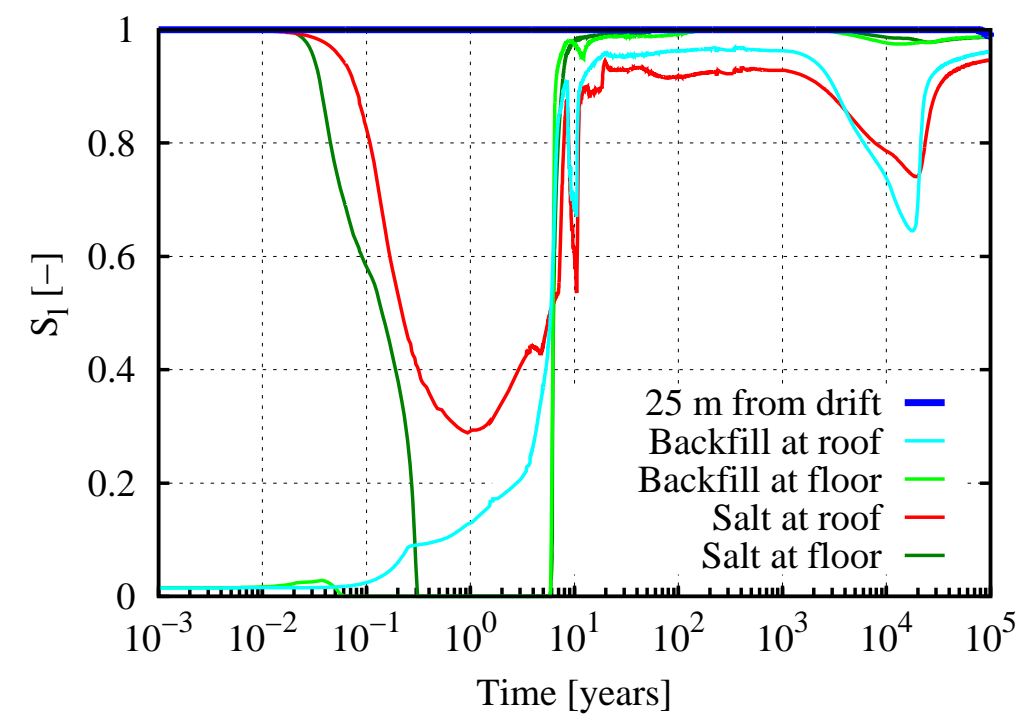

Backfill at roof

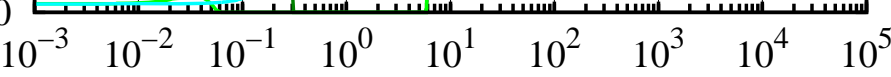

Time [years] 
Figure 13a (black\&white for printed version)

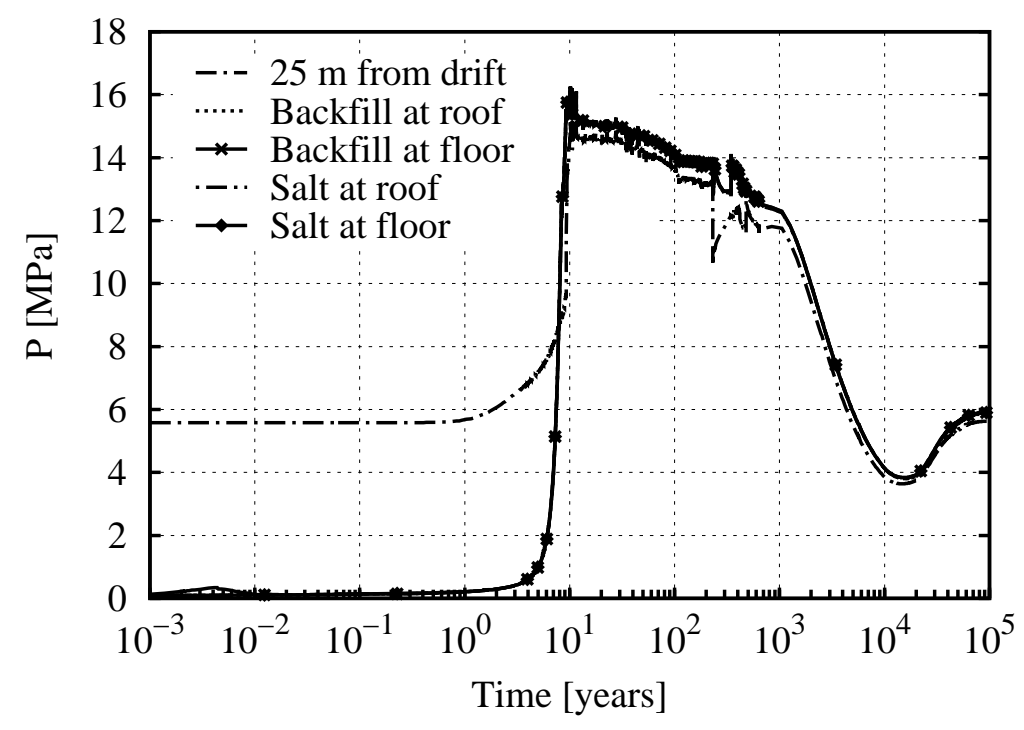


Figure $13 b$ (black \&white for printed version)

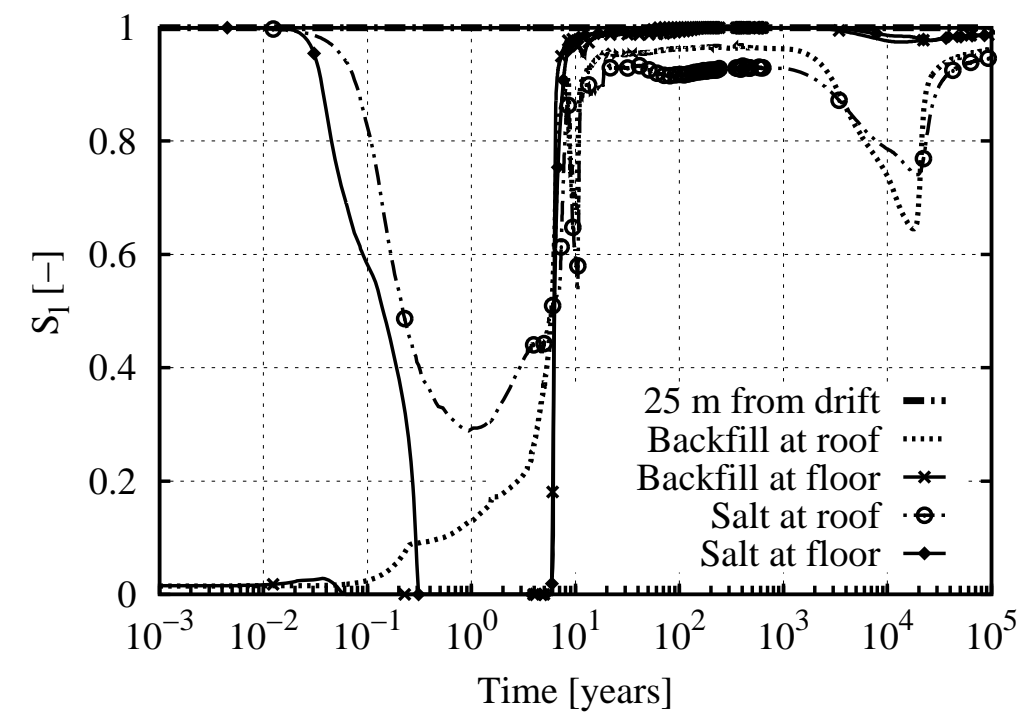


Capillary forces

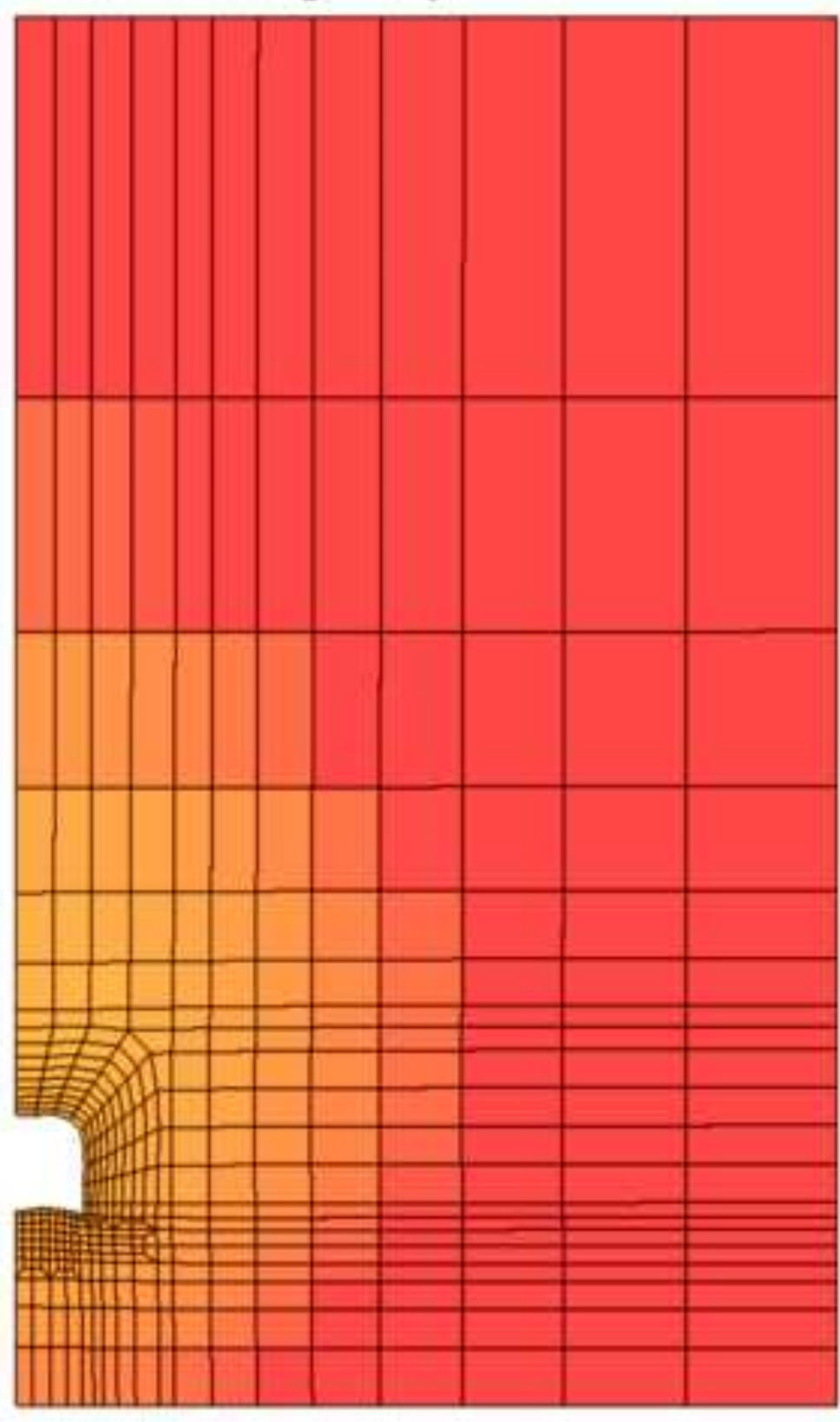

No capillary forces

$$
S_{l}[-]
$$

$1.000 E+00$ $9.874 \mathrm{E}-01$

$9.748 \mathrm{E}-01$

$9.622 \mathrm{E}-01$

9.496E-01

9.370E-01

9.244E-01

9.118E-01

8.992E-01

8.866E-01

8.740E-01

8.614E-01

8.488E-01

8.362E-01

8.236E-01

8.110E-01

7.984E-01

$7.858 \mathrm{E}-01$

7.732E-01

7.606E-01

7.500E-01

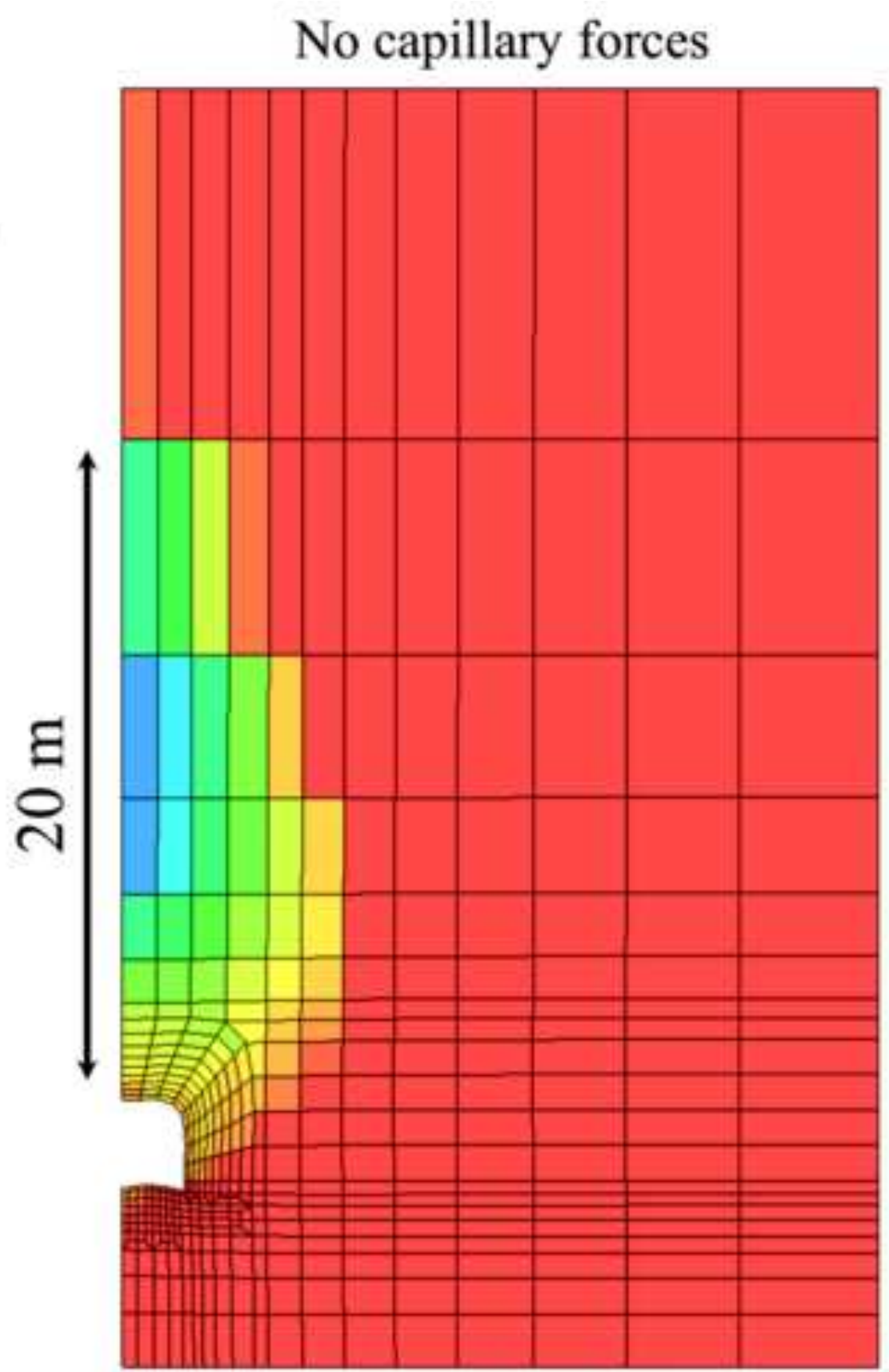


Capillary forces

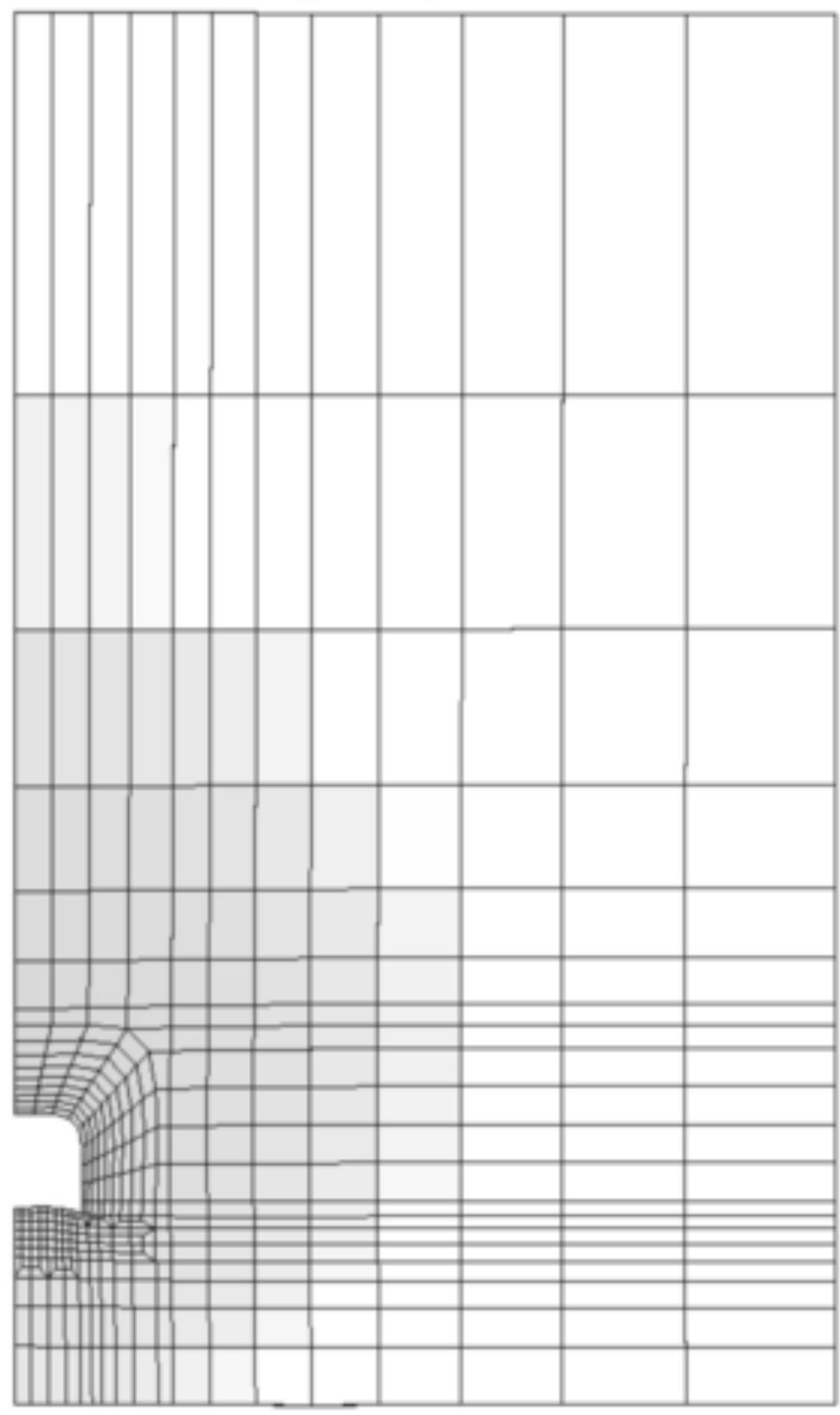

No capillary forces

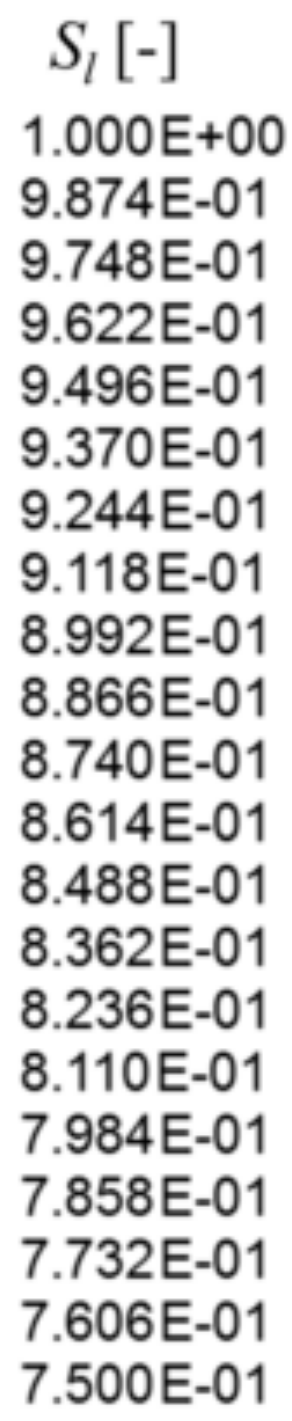

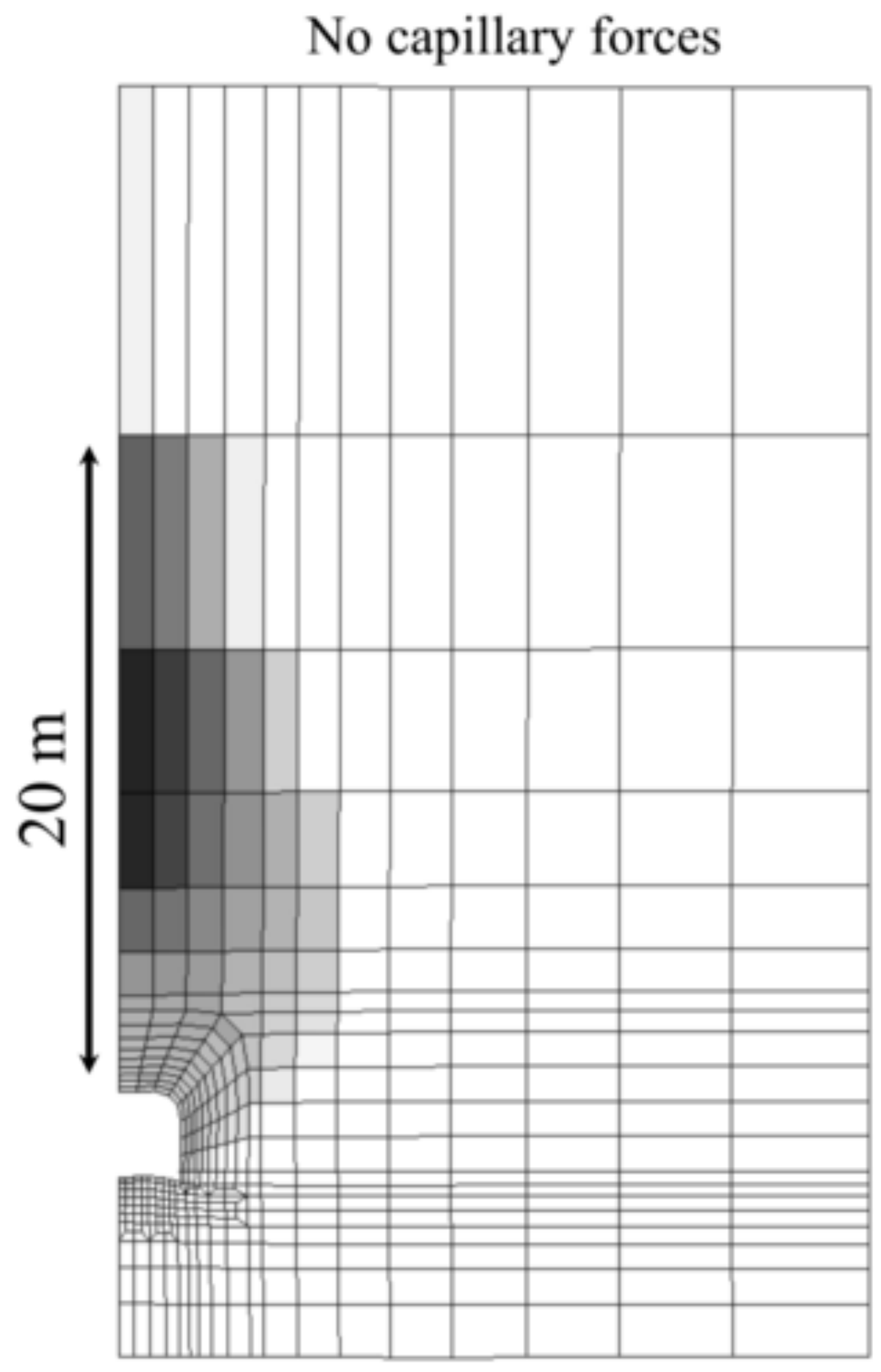

